$$
\begin{aligned}
& \text { أثر استخدام برنامج حاسب آلي تعليمي مقترح على } \\
& \text { تحصيل طالبات الصف الثاني الثانوي لمادة الاحياء }
\end{aligned}
$$

$$
\text { إعداد }
$$

أ/ مي بنت حمود بن سعود آل جاسر

تقنيات التعليم ـ كلية التربية

جامعة الأميرة نورة بنت عبد الرحمن التربة 


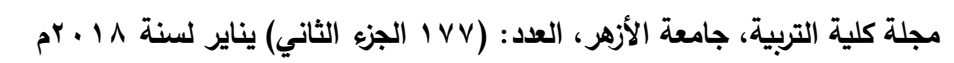

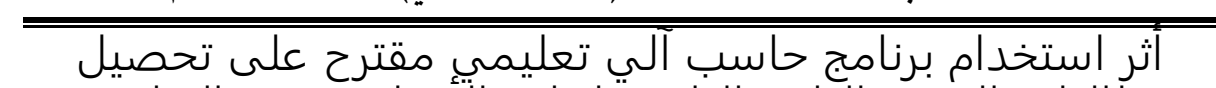

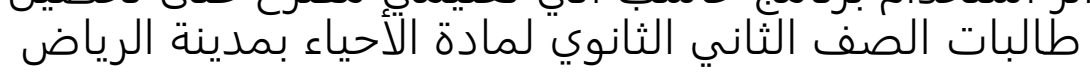
مستخلص البحث:

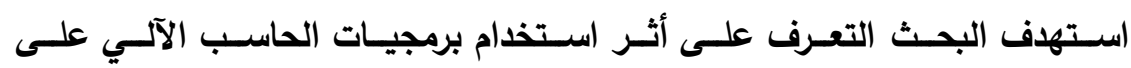

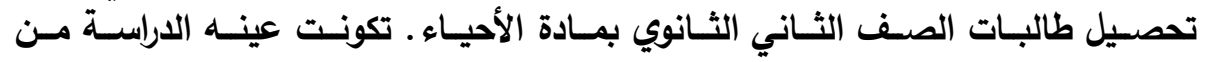

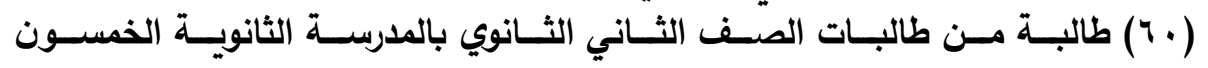

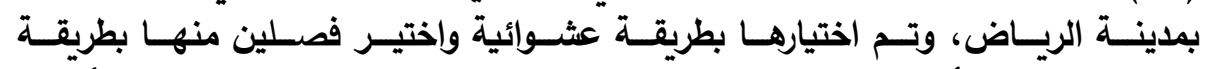

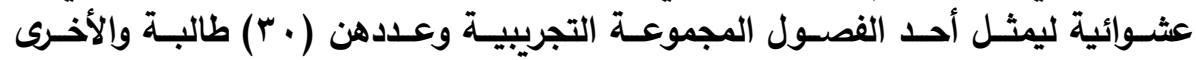

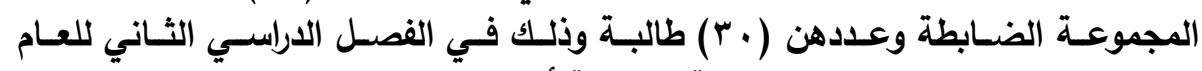

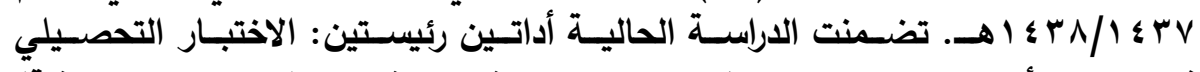

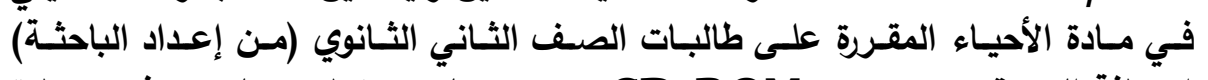

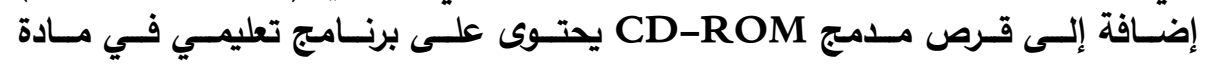

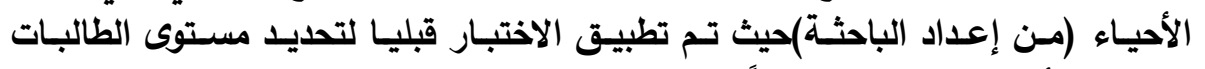

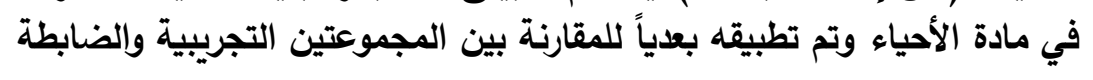
وتوصلت الدراسة إلى النتائج التالية:

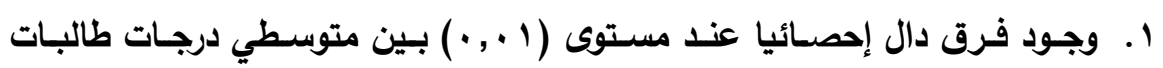

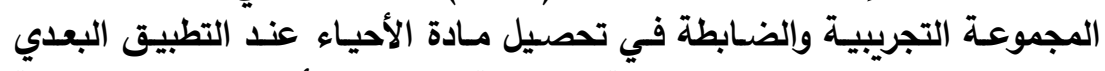

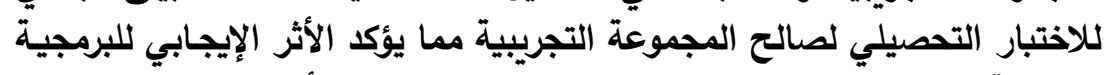
التعليمية في الرفع من مستوى تحصيل الطالبات في مادة الأحياء.

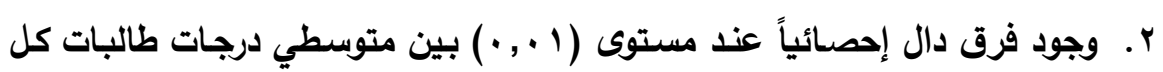

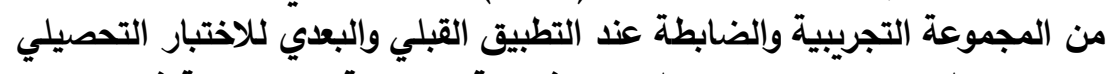

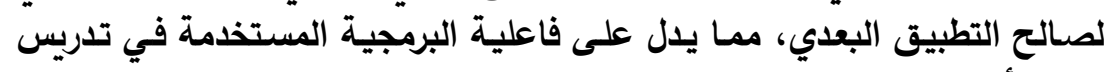
مادة الأحياء على التحصيل. 
مقدمة الدراسة:

لقد شهر العالم منذ بدايات القرن الحادي والعشرين فترة تغيرات هائلة أحدثت

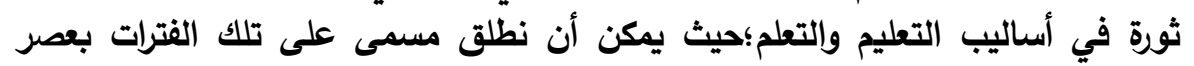

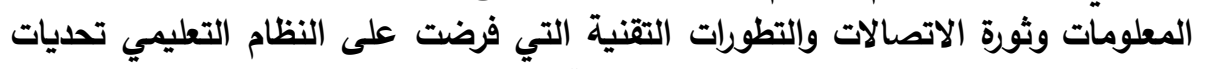

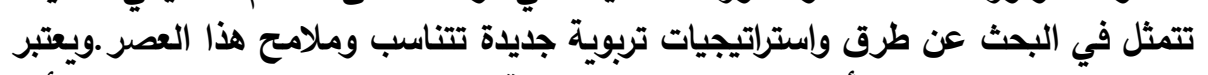

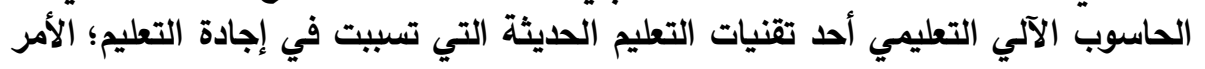

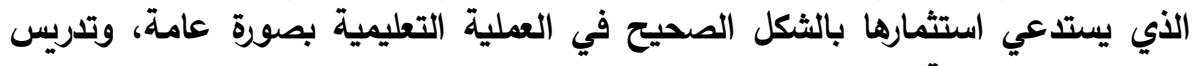
العلوم بصورة خاصة.

وقد قامت المؤسسات التعليمية باستخدام الوسائل التعليمية وتقنيات التعليم في

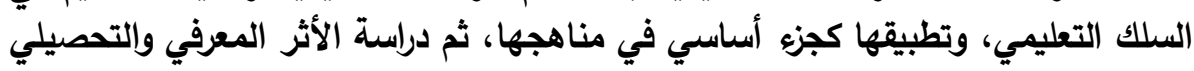

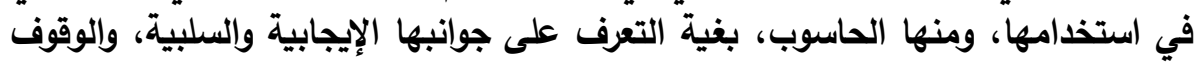

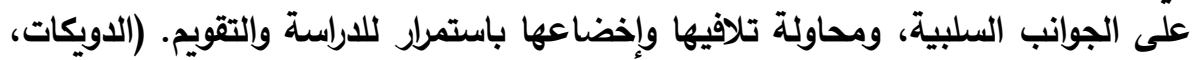

( $\{V r: Y \cdot 11$

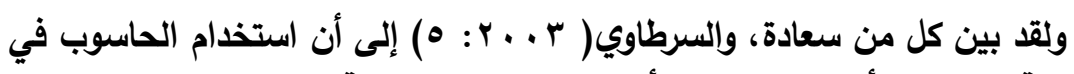

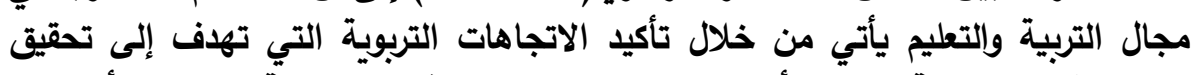

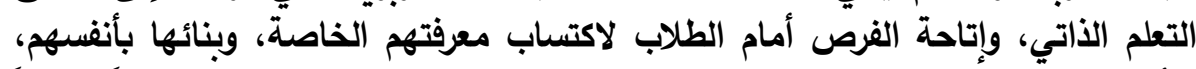

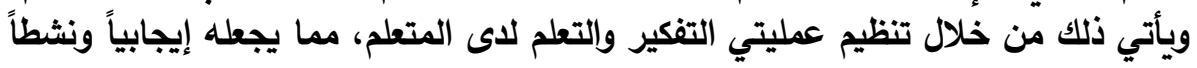

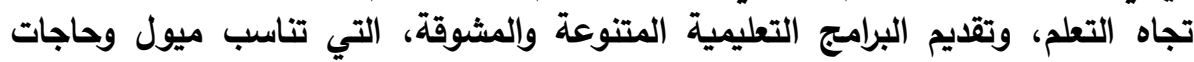

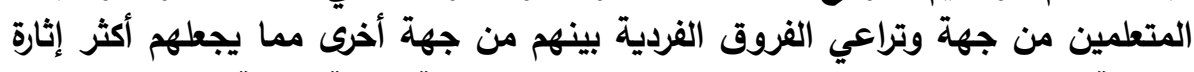

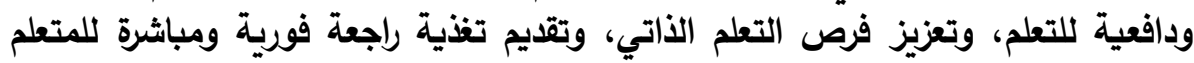

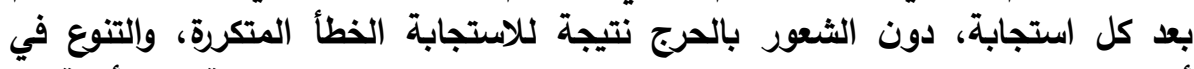

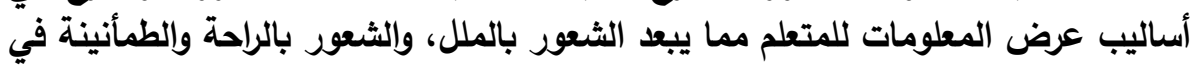

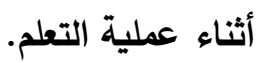

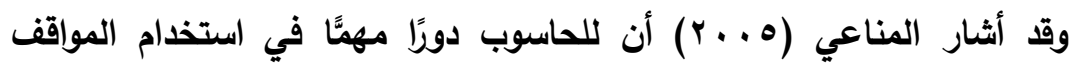

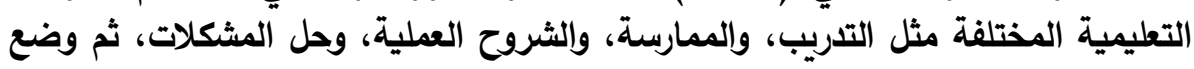

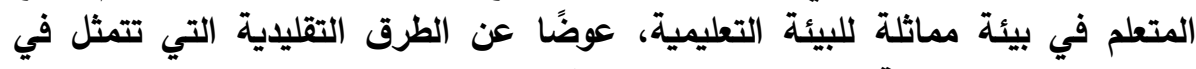
الكتاب المدرسي بواسطة التركيز على التعليم الذاتي.

إن وجود الحاسوب التعليمي في مجال التعليم أحلث تغيرات نوعية في القدرة

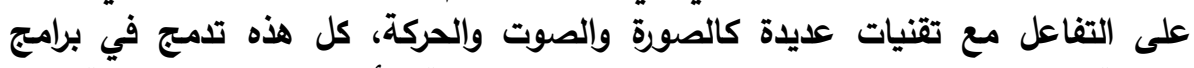

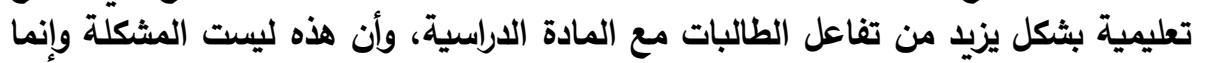

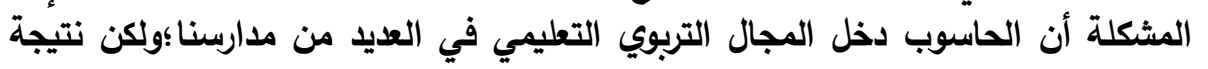




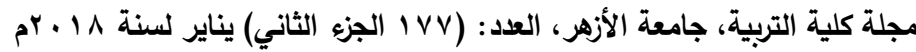

لغلبة الطريقة التقليدية في تدريس نجد أن معظم المعلمات والطالبات لا يعرفن كيفية

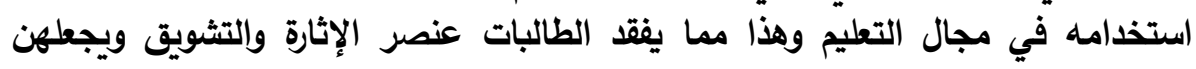

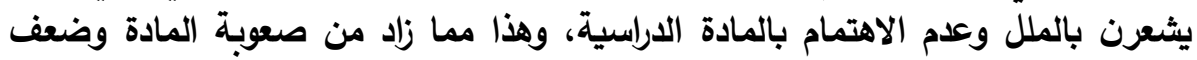

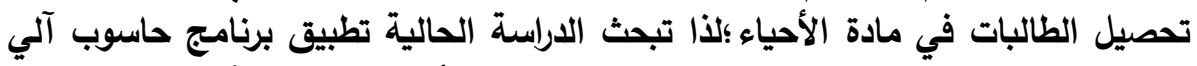

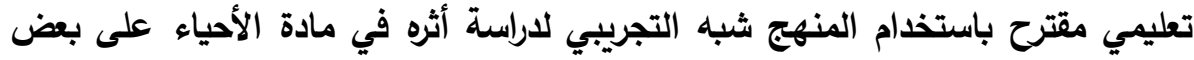

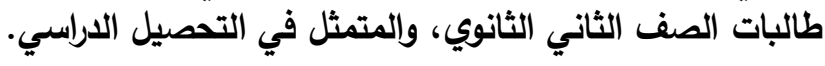

مشكلة الادراسة:

نتيجة لما تبرزه بعض الدراسات التي استخدمت برامج الحاسب الآلكي في زيسادة

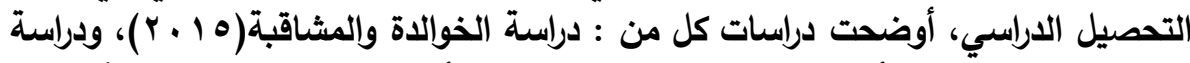

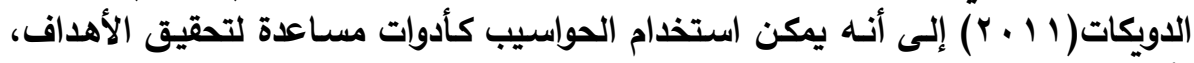
وأن استخدام الحاسوب في تدريس العلوم يؤدي إلى زيادة تحصيل الحيل الطلاب العلمي في مادة الأحياء والكيمياء.

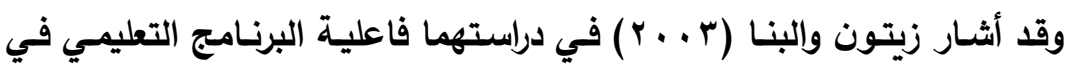

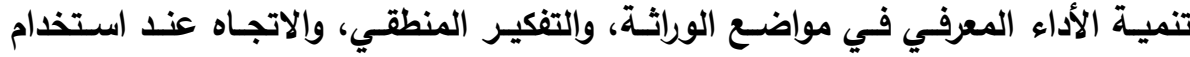
الحاسوب لاى عينة من طلاب الثانوية العامة في جمهورية مصر العربة العربية.

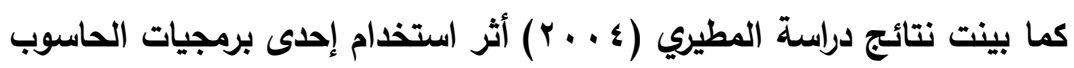

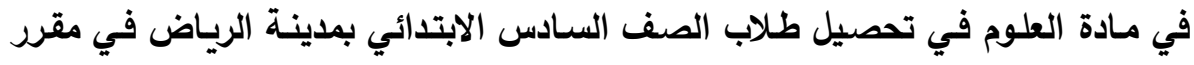
العلوم باستخدام المنهج التجري فيبي

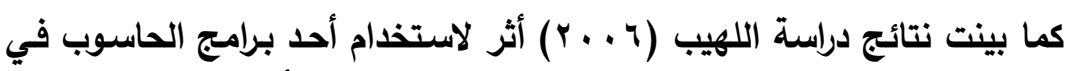

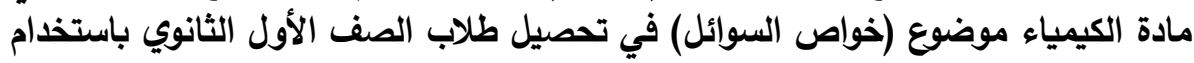
المنهج التجريبي

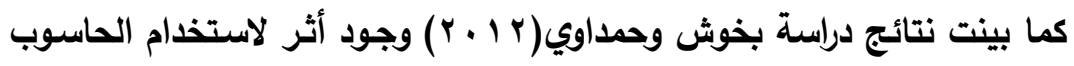
التعليمي على تحصيل تلاميذ الثالثة ثانوي علمي في مادي بادة العلوم الطبيعية

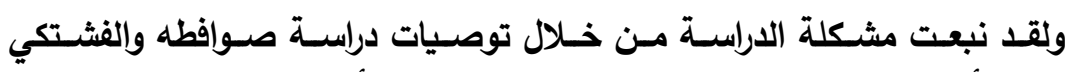

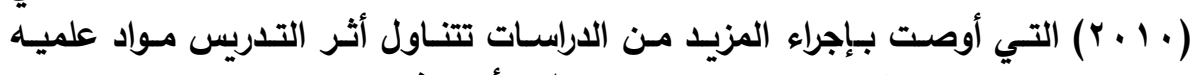

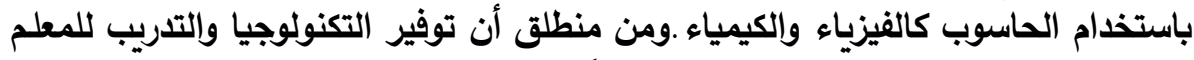

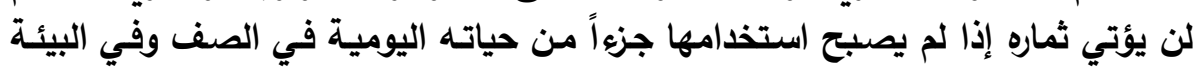

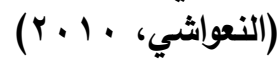

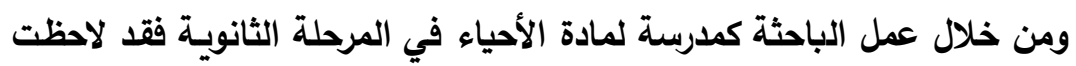

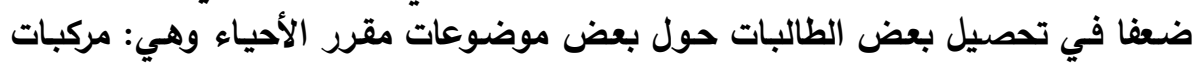




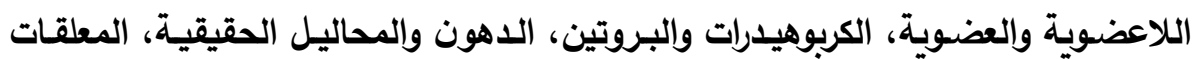

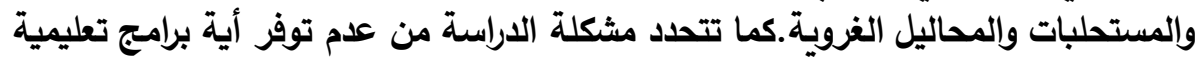

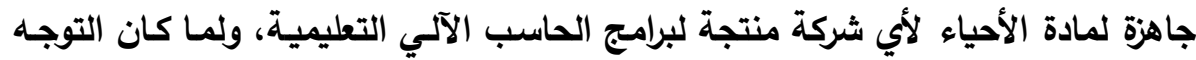

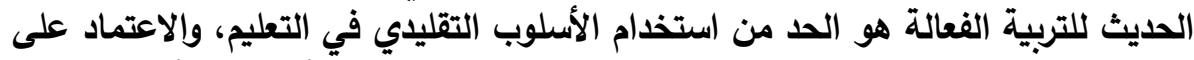

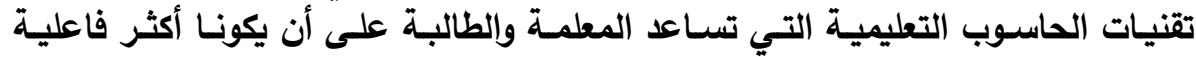
وإيجابية في العملية التعليمية.

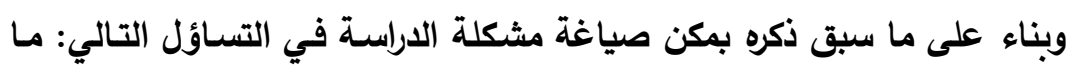

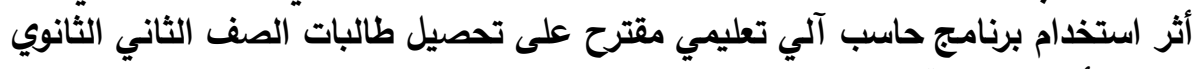
لمادة الأحياء بمدينة الرياض؟ برنج هدف الاراسة:

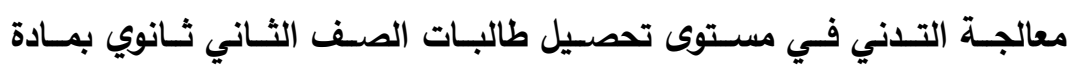

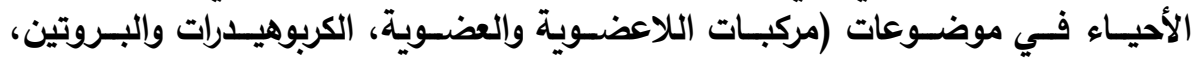
الاهون والمحاليل الحقيقية، المعلقات، والمستحلبات والمحاليل الغروية).

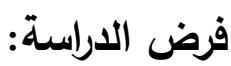

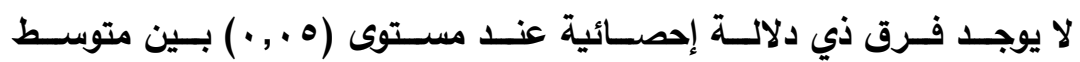
درجات طالبات المجموعة التجريبية والضابطة في تحصيل مادة إحصائل علأحياء.

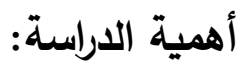

تبرز أهمية الدراسة الحالية من خلال إسهامها في النواحي التالية:

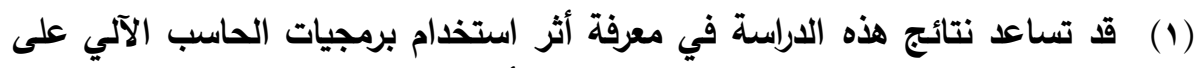
تحصيل طالبات الصف الثاني الثانوي لمادة الأحياء.

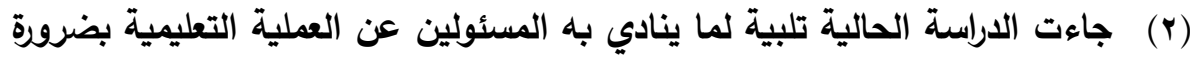

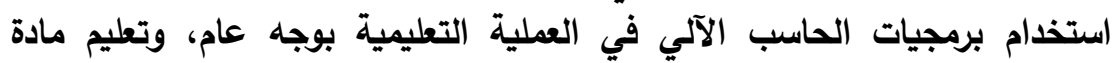

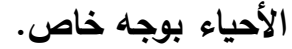
استخدمت الاراسة الحالية أسلوب تدريس مادة الأحياء بواسطة برمجيات الحاسب الآلي مما قد يسهم في زيادة التحصيل. 


\section{حدود الدراسةة:}

اقتصرت الدراسة الحالية على الوحدة الثانية لطالبات المدرسة الخمسون الثانوية

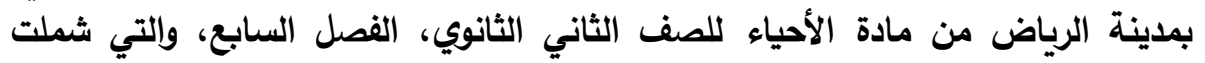

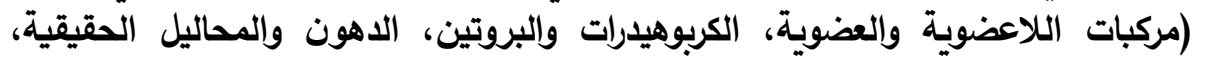

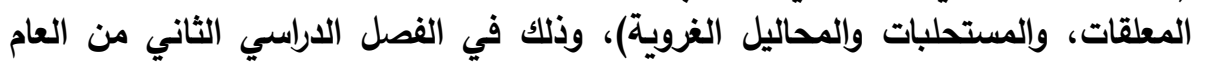

.

$$
\text { مصطلحات الاراسة: }
$$$$
\text { 1- 20 - الحاسب الآلي: }
$$

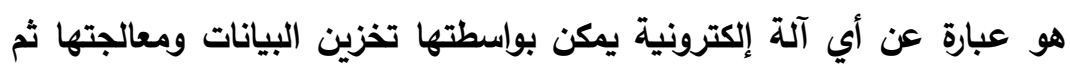

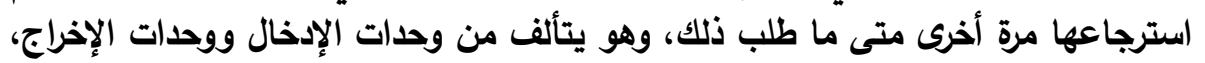

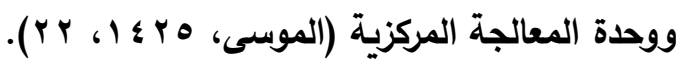

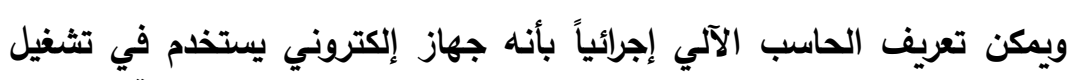
وعرض البرنامج التعليمي الذي سبق برمجته من قبل المختصين في وزارة التربية والتعليم.

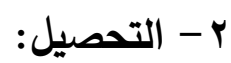

يعرف بأنه النتيجة المكتسبة لإنجاز أو تعلم شيء ما بنجاح ومهارة

.(oxford,1998,p9)

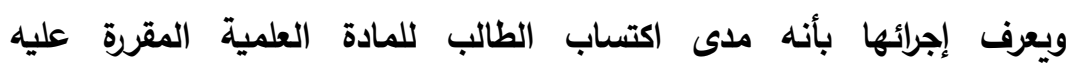

واسترجاعها عندما يُطلب منه ذلك، كما يقسمها المقياس المستخدم في هذه الدراسة.

$$
\text { r - برمجيات الحاسب الآلي: }
$$

هي نوع من التعلم الأتي يقوم على أساس تقسيم المادة التعليمية إلى أجزاء

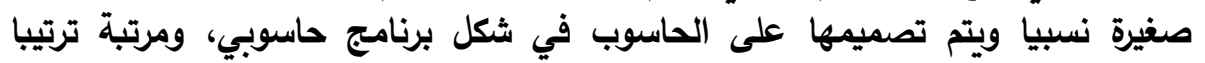

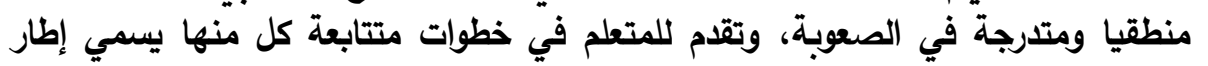

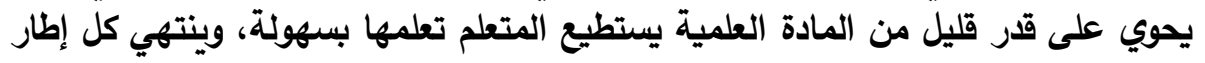

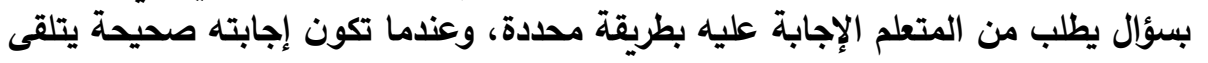

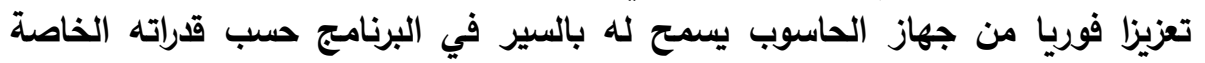

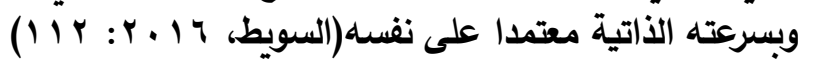

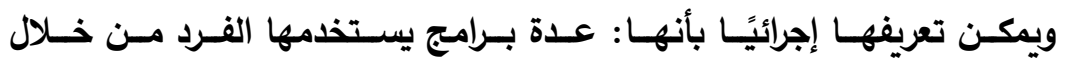

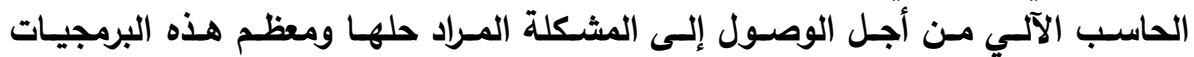




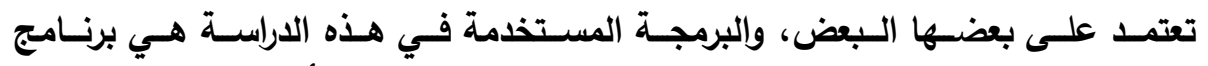

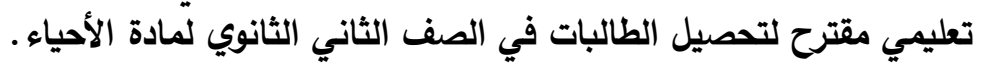
الإطار النظري والدراسات السابقة: المبحث الأول: الإطار النظري:

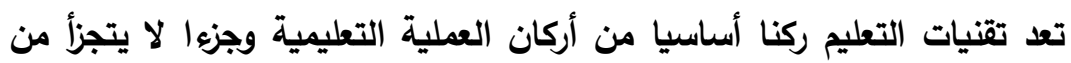

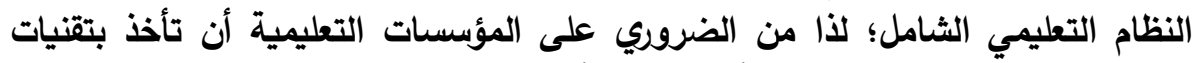

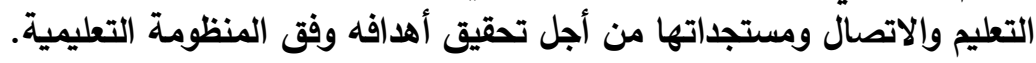

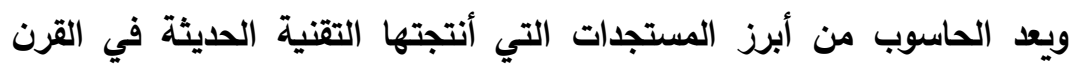

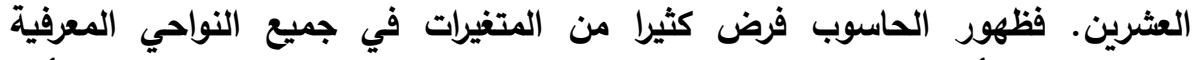

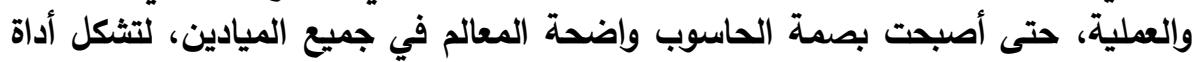

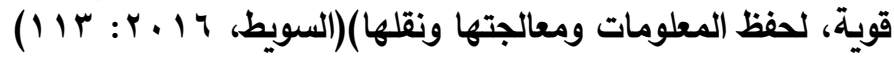

ويعتبر مقرر الأحياء من أهم مقررات العلوم الطبيعية التي تربط الطالب بالبيئة

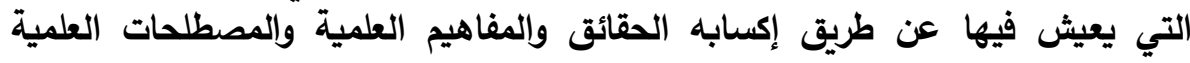

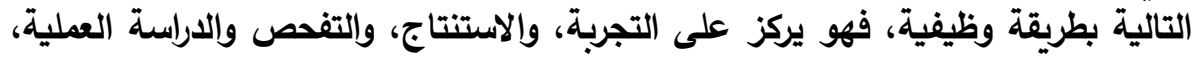

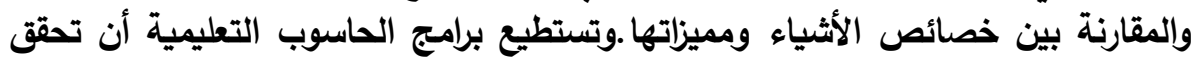

ويعرف الحاسوب التعليمي على أنه: "توع من التعليم الذاتي يتم بواسطة

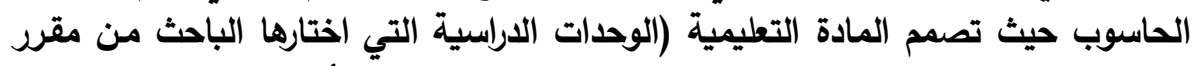

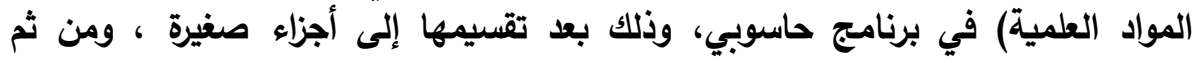

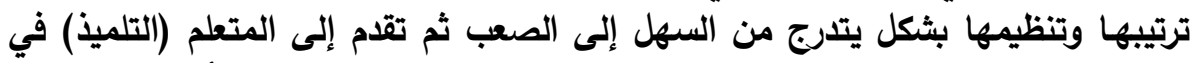

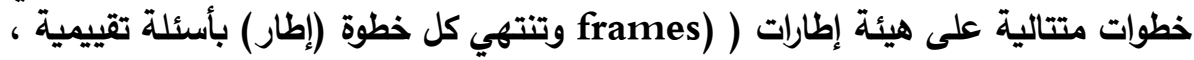

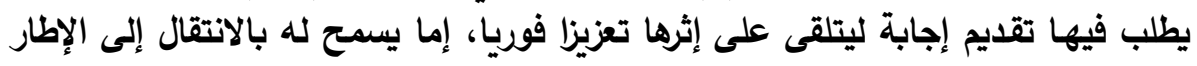

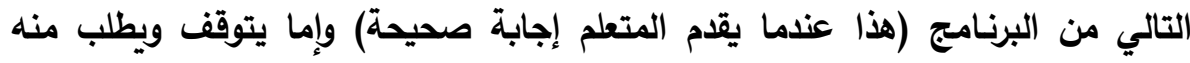

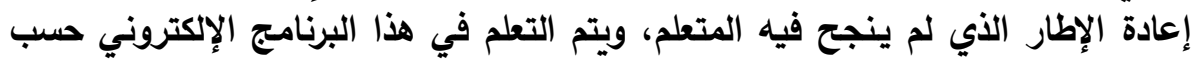

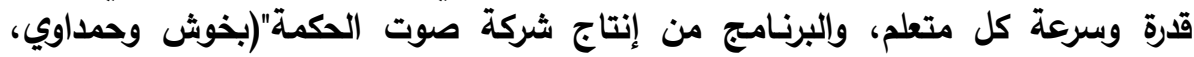

(rrA: $r \cdot 1 r$

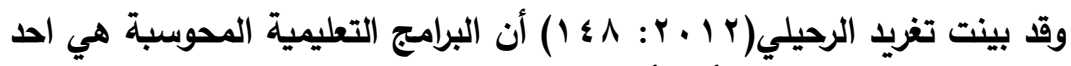

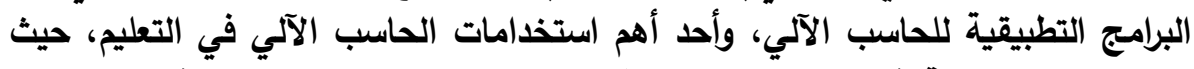

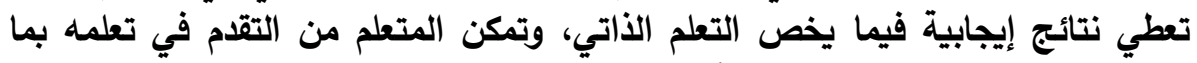

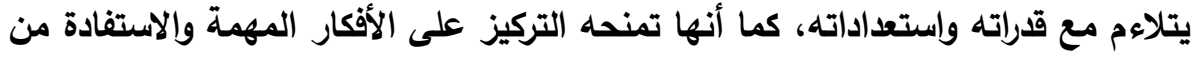




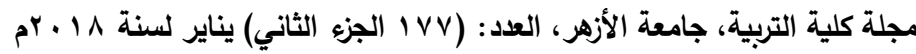

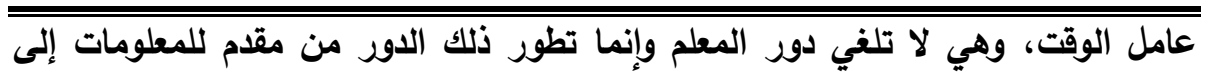

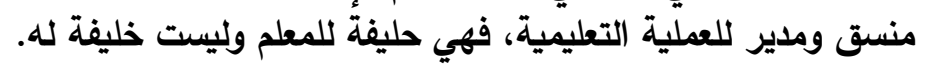
أولا: أهداف إدخال الحاسوب في مؤسسات التعليم من أهم أهداف إدخال الحاسوب في مؤسسات التعليم السعودية ما يلي:

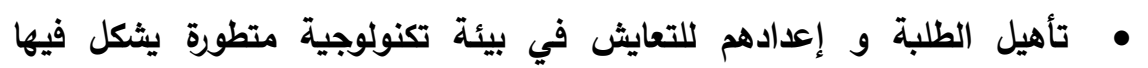

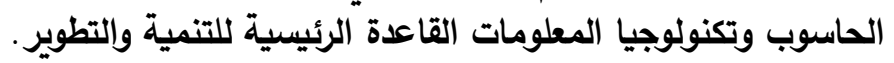
• تصسين أساليب التدريس عن طريق إدخال الحاسوب كوسيلة تعليمية.

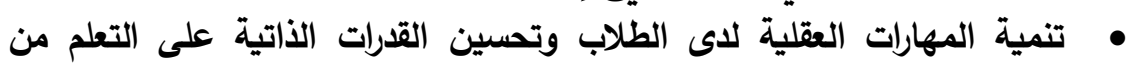

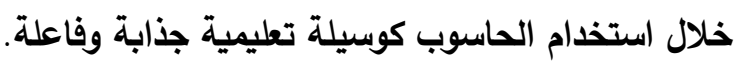
• تنمية روح العمل الجماعي بين الطلبة عن طريق أسلوب التعلم التعاوني.

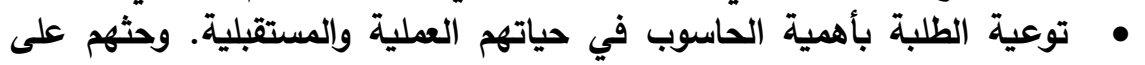

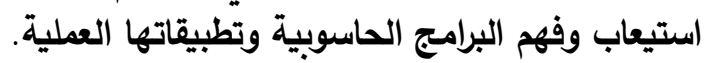

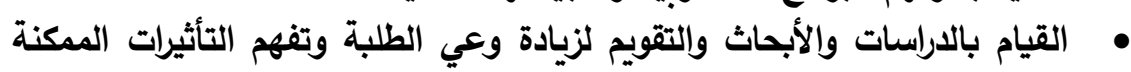

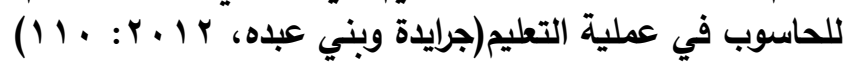

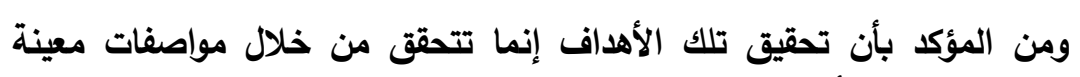

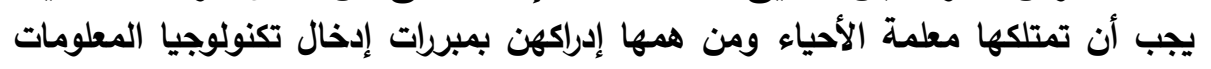

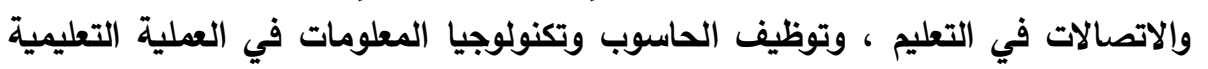
بصورة معتادة وفعالة. ثانيا: استخدام الحاسب الآلي كوسيلة مساعدة في التعليم: بعد التعرف على مزايا ومبررات استخدام الحاسب في التعليم يتم التطرق إلى الى التى

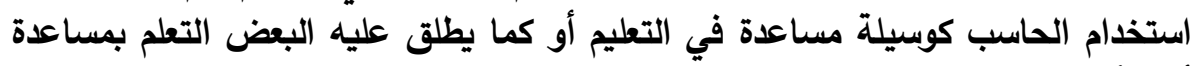

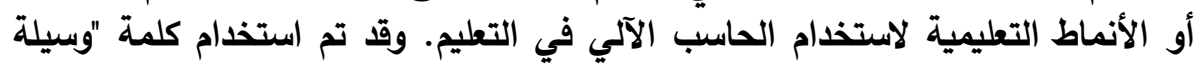

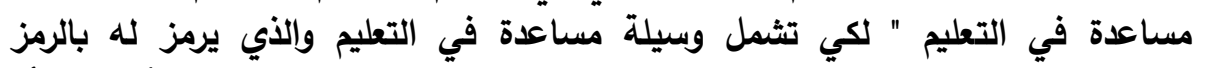
في الولايات المتحدة الأمريكية أو الويز

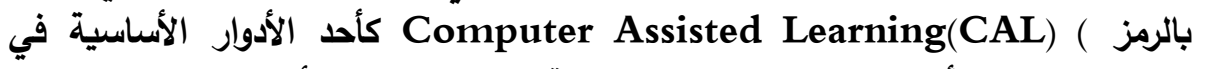

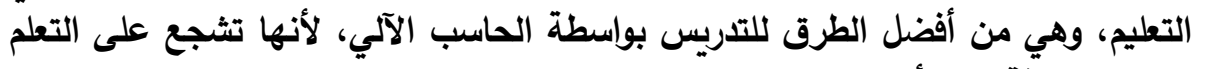

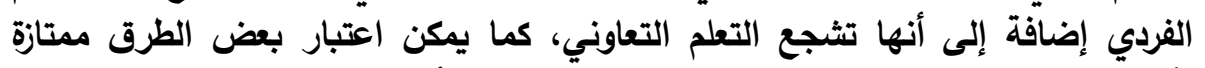

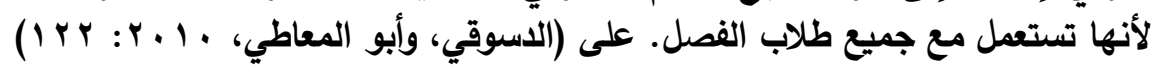

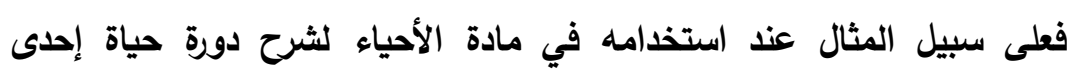

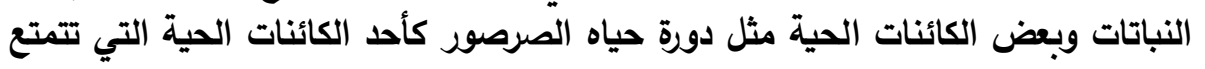


بدوره حياة منتظمة فإنه يمكن عرضها على مجموعة من الطلاب كنوع من التعلم التعاوني

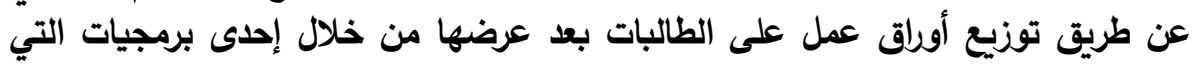
تثرح دورة الحياة. ثالثا: برامج الحاسب الآكي التعليمية: 1-مفهوم البرمجيات التعليمية: وتعرف البرمجيات التعليمية بأنها: مجموعة المكونات المنطقية التي تقدم في التئي

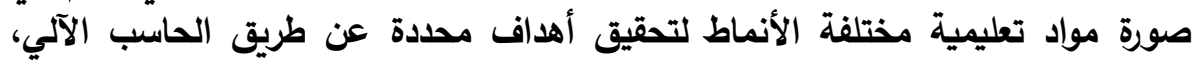

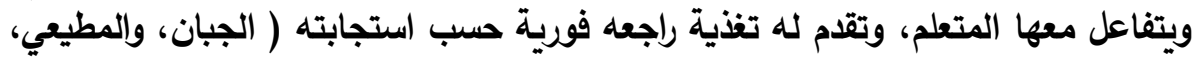
$(V 4: Y \ldots \varepsilon$

كما تعرف بأنها"طريقة تفاعلية في التعلم يستخدم فيها الحاسب لعرض العتو ما يراد

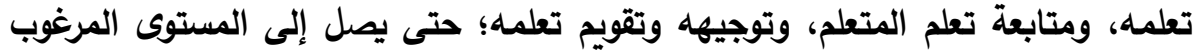

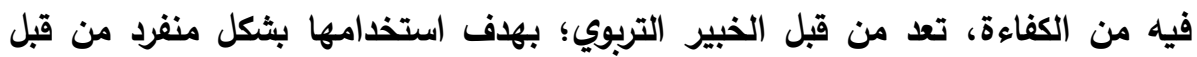

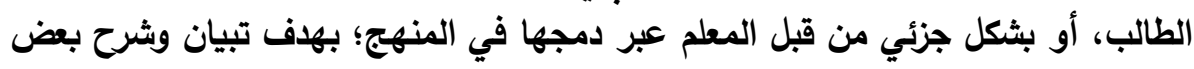

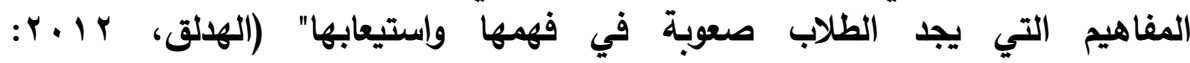

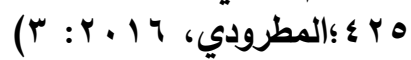

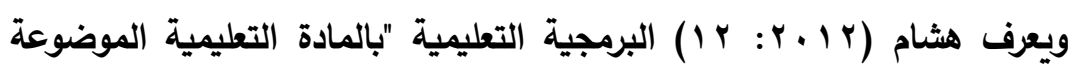

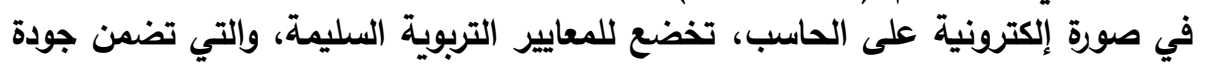

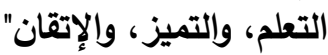

وتعرف في الاراسة بموضوعات المنهج الدراسي لمادة الأحياء للصف الثاني

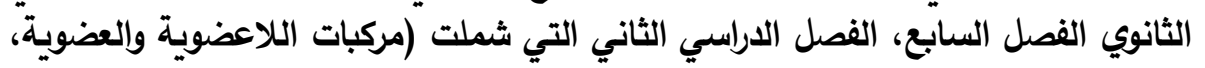

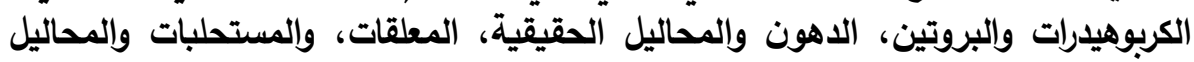
الغروية)، و التي تمت برمجتها إلكترونيًّا عن طريق العتئي الحاسب الآلي؛ بحيث تستطيع المعلمة استخدامها.

r-فوائد تطبيق برامج الحاسب التعليمية

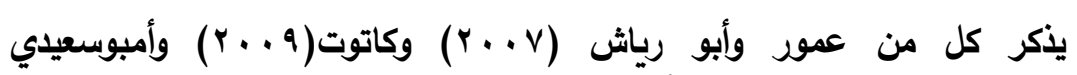

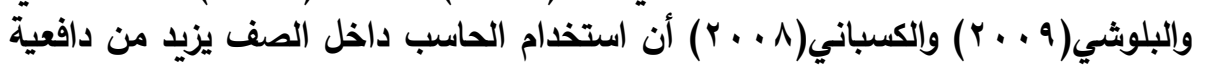




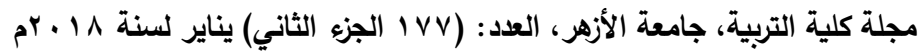

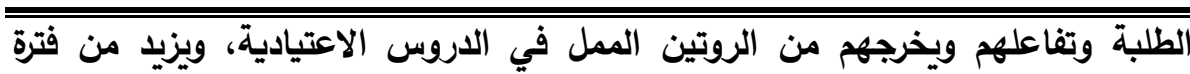

الاحتفاظ بالمفاهيم لفترة زمنية أطول.

أما سالم (ه . . ץ: 11 1 1) فيعدد فوائد تطبيق برامج الحاسب التعليمية في الآتي:

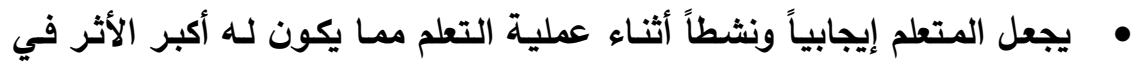

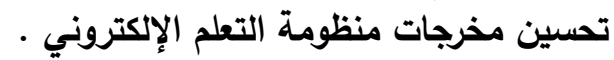

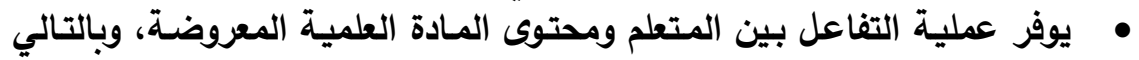

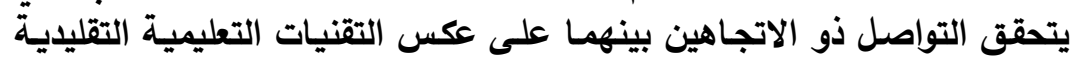
مما يعوض عدم وجود المعلم أثناء عملية التعلم لبعد المكان.

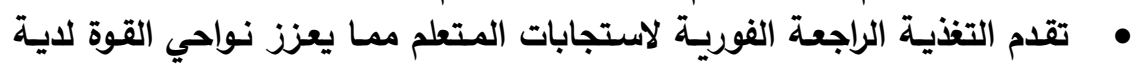

ويعالج نقاط الضعف.

لا يعتبر المتعلم في موقف المستقبل السلبي بل يحاوره الحاسب الآلي ويقدم لـه

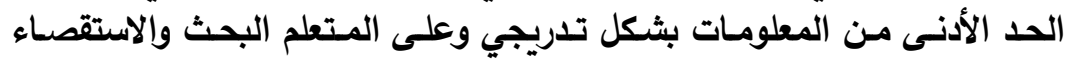

والاكتشاف للوصول إلى بقية المعلومات المترابطة بجانب المواتيك المواضيع المختلفة.

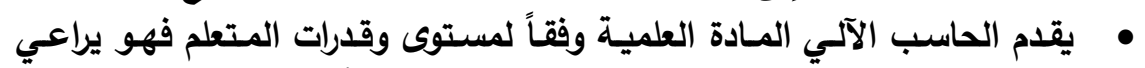
الفروق الفردية بين مستويات المتعلمين المختلفة وكذا أنماط التعلم المختلفة مما يساعد في تحقيق مبدأ تفريد التعليم.

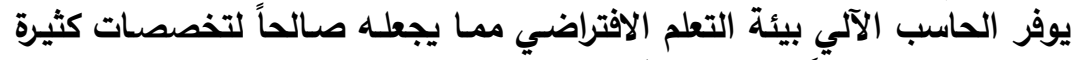

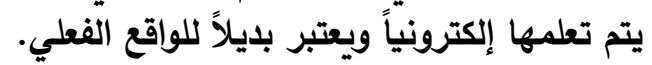

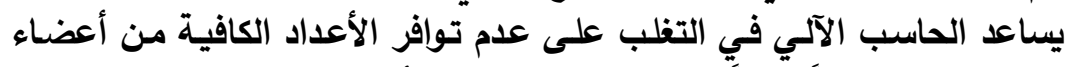

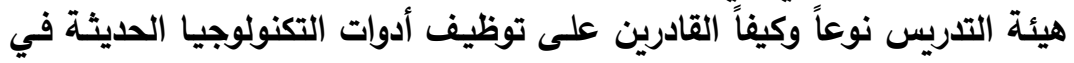

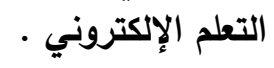

r-خصائص البرمجيات التعليمية الجيدة:

تعبر البرمجيات التعليمية الجيدة عن منظومة تعليمية متكاملة وشاملة بما

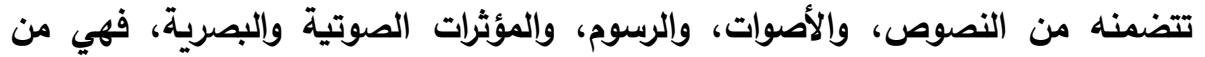

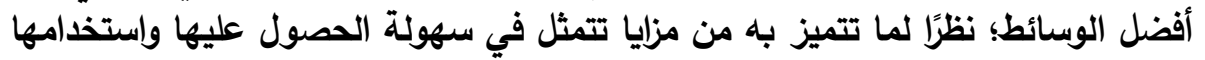

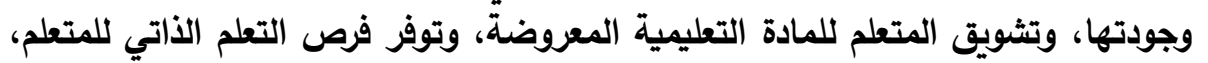

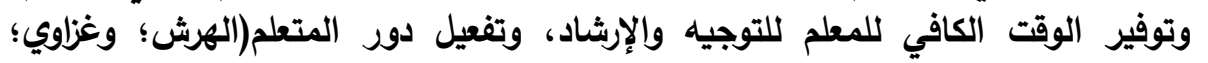

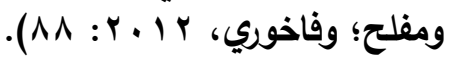

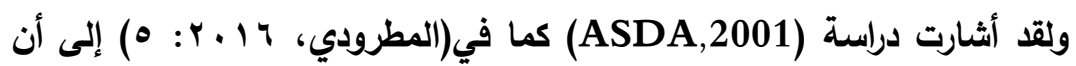

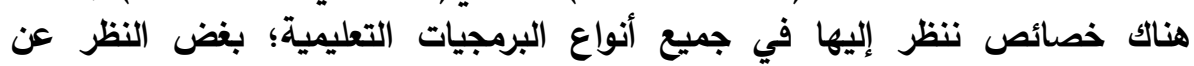
المحتوى، والأهداف أو المستخدمين؛ حيث ينبفي أن تستفيد المناهج التعليمية من ميزات التئية 


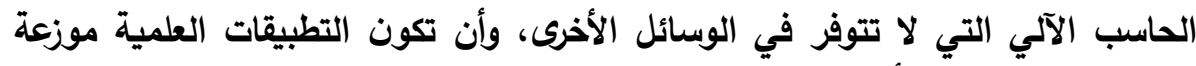

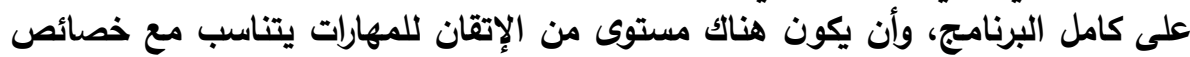

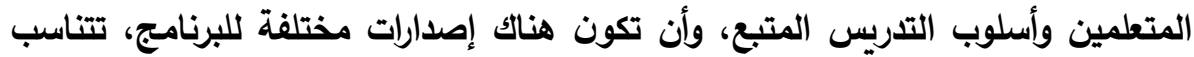
وتتكيف مع اختلاف خصائص المتعلمين وتعدد حاجاتهم.

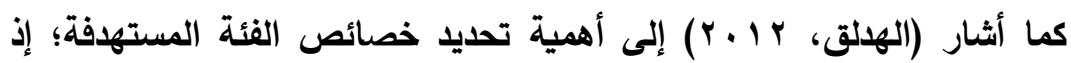

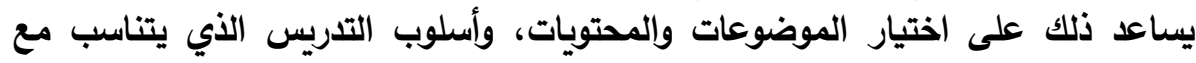
مستواهم العقلي. ع - المواصفات والمعايير التربوية التي ينبغي مراعاتها عدد تصميم البرمجيات الحاسوبية التعليمية

من أهم المواصفات والمعايير التربوية التي ينبغي مراعاتها عدد تصميم البرمجيات الحاسوبية التعليمية، ما يلي: أهماصئ والمعايل أ- أهداف البرمجيات الفعالة:

تعدّ الأهداف حجر الزاوية في العملية التعليمية، وهي بمثابة التغيرات المراد

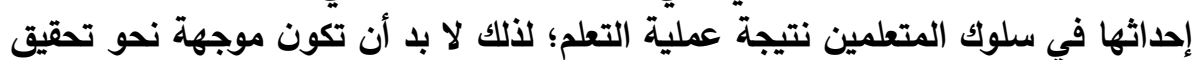

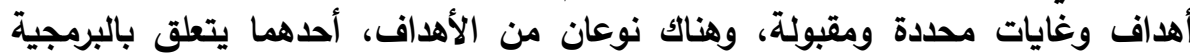

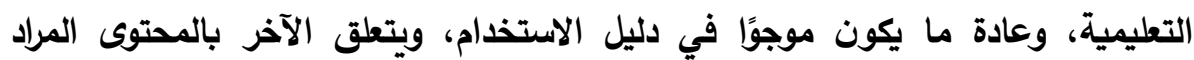

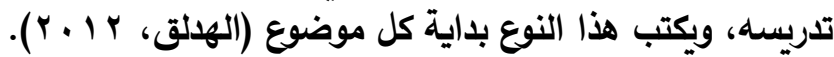

ومن الشروط الواجب توفرها في الأهداف: أن تكون مصوغة بصورة سلوكية يمكن قياسها، وأن تتنوع هذه الأهداف، بحيث الأبه تثمل الجوافت الجوانب المعرفية بمستوياتها

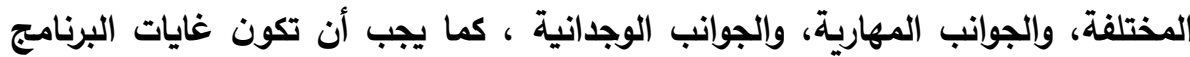

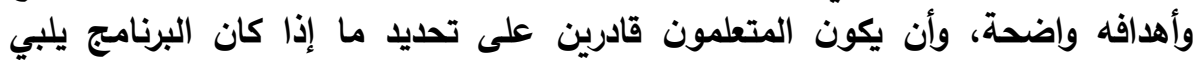

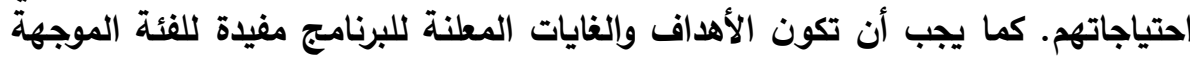

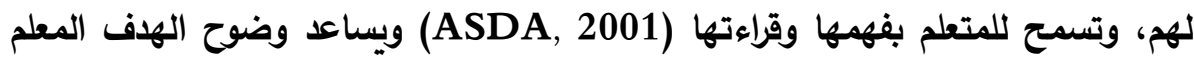

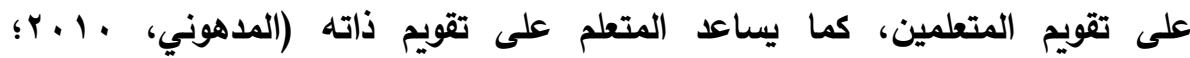

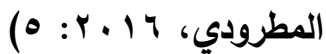

إن عملية تحديد الأهداف متطلب أساسي لرسم الهيكل العام للبرنامج، ورسم

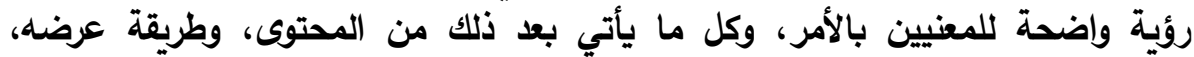

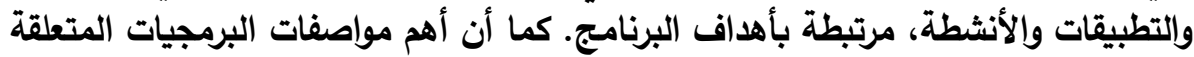
بالأهداف: 


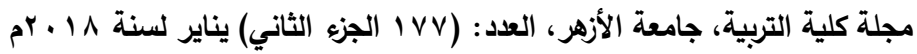

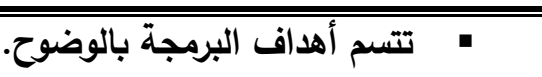

• تتنوع الأهداف بحيث تثمل الجوانب المعرفية، والمهارية، والوجدانية. • تُصاغ الأهداف بطريقة يسهل فهمها للمتعلم.

• لبي البرمجية احتياجات المستفيد من خلال الأهداف الموضحة فيها. • تتم صياغة أهداف البرمجيات بطريقة سلوكية يمكن قياسها. ب - محتوى البرمجيات العلمي الجيد:

يُقصد بالمحتوى: مجموعة الخبرات المعرفية، أو الحركية، أو الوجدانية التي التي

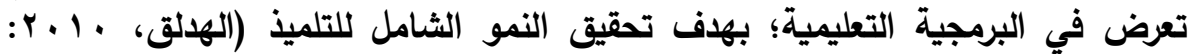

والمحتوى العلمي الجيا ينبغي أن يكون:

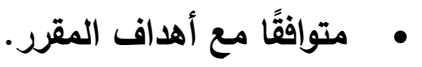

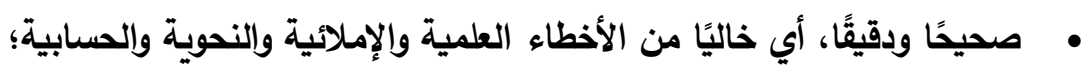
وأن لا يعلم الطلاب معلومات ومهاريات الآنات خاطئة. • خالًا من التحيز لعرق أو جنس أو دولة وغيرها. • مناسبًا لخبرات الطلاب السابقة ولمستوى نموهم من حيث الحقائق والمفاهيم والمهارات التي يقدمها، ومن حيث لغتها وتنظيمها وأسلوبها. • اليًا من الأثشياء المحرمة والمنافية للدين والأخلاق كالصور الإباحية

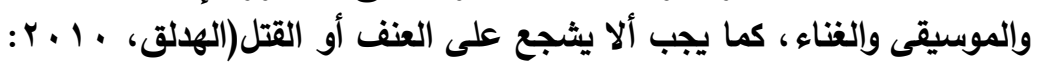
. ( $\{$ r 9 إضافة إلى ما سبق يجب التأكيد على أهمية مراعاة الفروق الفردية عند اختيار المحتوى، وأن يُعرض بصورة تتيح للمتعلم فرصة الاختيار . إن أهم مواصفات البرمجيات المتعلقة بالمحتوى، أنها: • عكس الأهداف من ناحية شموليتها، ومراعاتها لمستوى الهرف المطلوب. • يركز على المواضيع المرتبطة بالأهداف التي تسهم في البناء المعرفي للمتعلم. • يتسم بالصحة العلمية. • يتناسب مع خبرات المتعلمين ومستوى نموهم. 


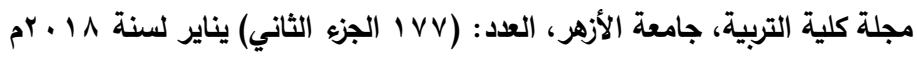

• يتيح تنظيمه للمتعلم التنقل بين الوحدات التعليمية وفقًا للتعلم الأاتي. • يراعي اختلاف أنماط المتعلمين. • يخلو من الأخطاء اللغوية الإملائية أو النحوية. • يخلو من الأمور التي تنافي الدين والأخلاق. • يخلو من التحيز لقضية معينة. • توضح البرمجيات آخر تحديث لمحتواها.

• تسهل الوصول لمواضيع البرمجيات التي حدثت دون استعراض ما تم عرضه

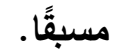
• ت أتوافر روابط كمراجع إضافية تسمح للمتعلم باستكشاف موضوع البرمجيات بثكل أوسع. • يتكون المحتوى من سلسلة من الاروس القصيرة، موزعة على عدة جلسات. • تتضمن البرمجية قاموسيًا للمصطلحات العلمية المستخدمة. • تستخدم الأدوات البيانية المرتبطة بالمحتوى، مثل: الصور، والرسوم، والجداول، والروابط، وغيرها. ج- دعم حافزيـة المستخدم للتعلم:

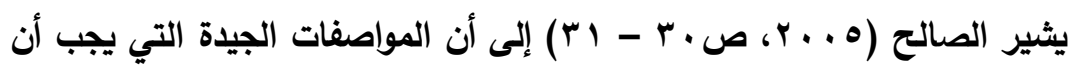

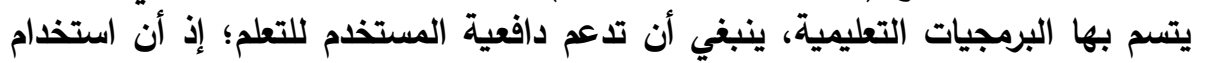

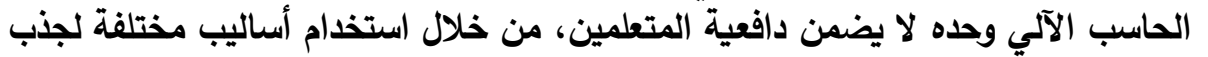

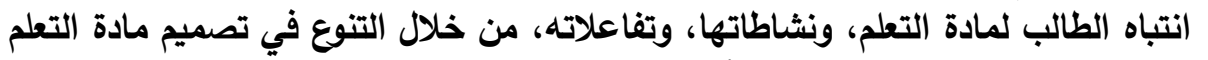

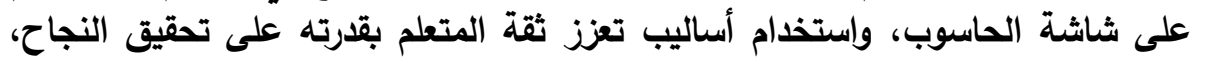

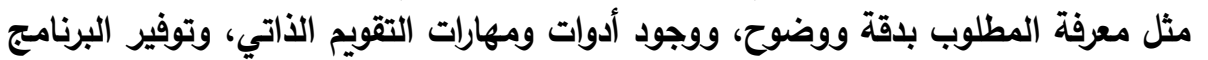

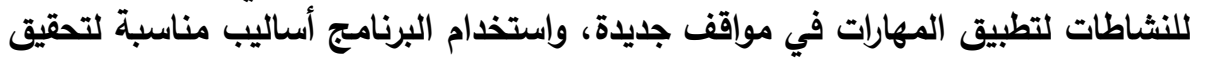

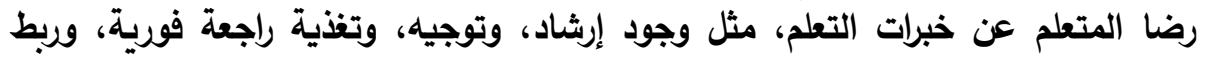

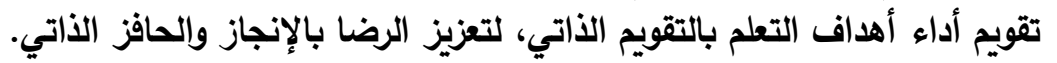

إن أهم مواصفات البرمجيات المتعلق بالحافزية، أنها: • الجذب المتعلم من خلال التنوع في تصميم مادة التعلم. • تدعم البرمجيات ثقة المتعلم بقدرته على النجاح. 


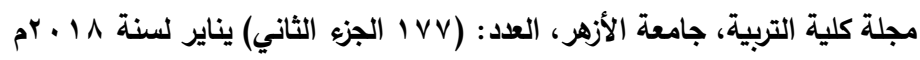

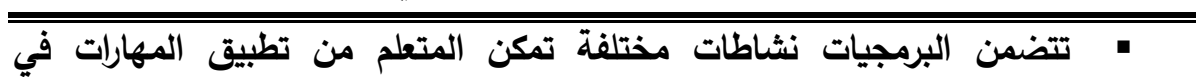
مواقف جديدة.

• تستخدم تقنيات تثير دافعية المتعلم، مثل الألعاب، والبيئة الاستكثافية.

$$
\text { • تحتوي البرمجيات على تغذية راجعة مشجعة. }
$$

• تحتوي البرمجيات على نشاطات قائمة على مهارات التفكير العليا.

• يتوع في البرمجيات مستوى التحدي والصعوبة مع ارتفاع مستوى المتعلم.

• ُشتخدم البرمجيات طرق عرض مشوقة لتقديم المحتوى العلمي، مثل: استخدام

الألعاب، والمحاكاة، والبيئة الاستكشافية، والعروض مرضئ لتصنيم التقديمية.

د - تحقيق التفاعل بين المتعلم والمحتوى:

إن التفاعل Interactivity بين المتعلم والمحتوى، وكذلك بين الطالب ومعلمه،

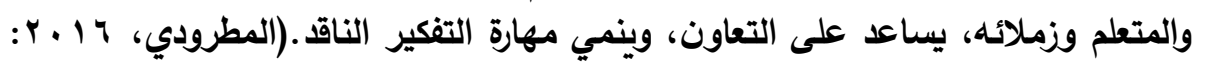

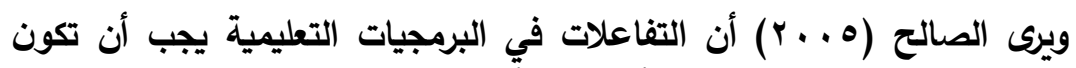

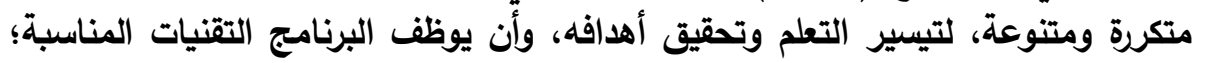

لتنفيذ التفاعلات المرغوبة ودعمها.

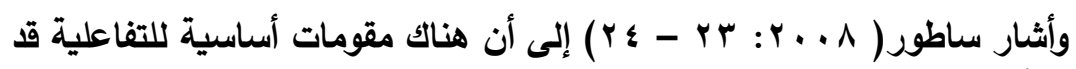

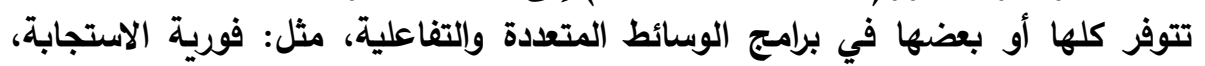

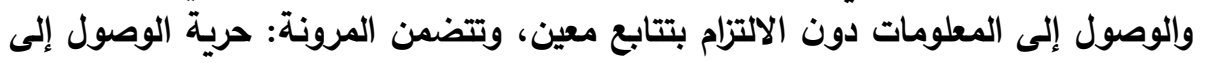

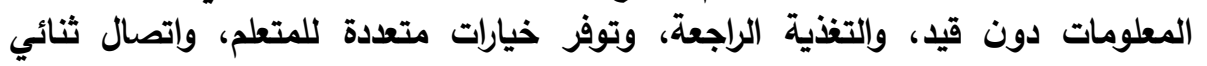

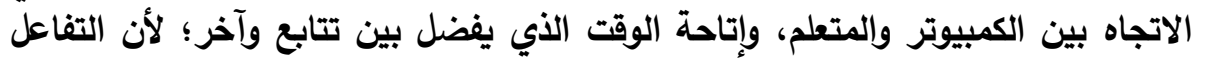

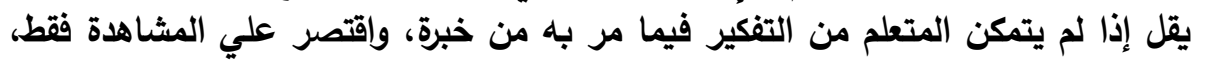

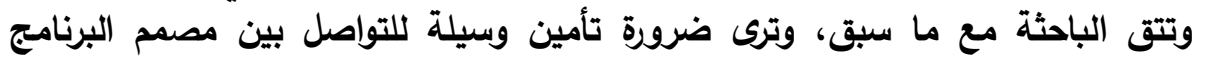

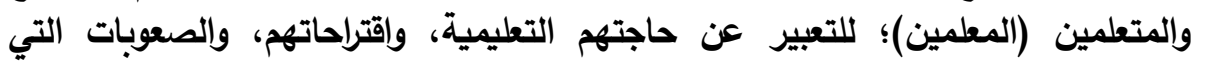
واجهتهم.

$$
\begin{aligned}
& \text { إن أهم مواصفات البرمجيات المتعلقة بالتفاعلية، هي: } \\
& \text { • تنوع التفاعلات مع استجابات المتعلم المختلفة. } \\
& \text { • توظيف التقنيات المناسبة لتنفيذ التفاعلات المرغوبة ودعمها. } \\
& \text { • الاستجابة للمتعلم بثكل فوري. }
\end{aligned}
$$




$$
\begin{aligned}
& \text { • توفير خيارات متعدة للمتعلم. } \\
& \text { هـ - تقويم البرمجيات لأداء المتعلم: }
\end{aligned}
$$

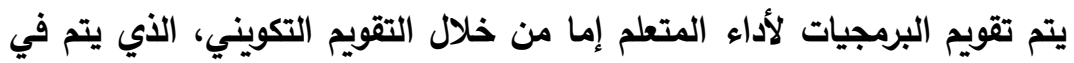

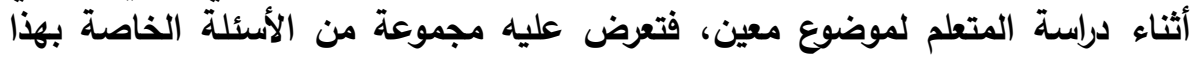

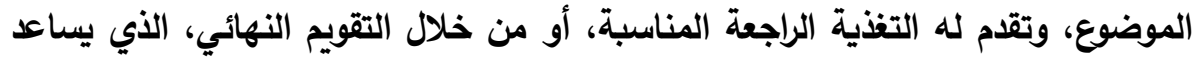

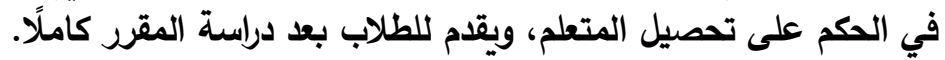

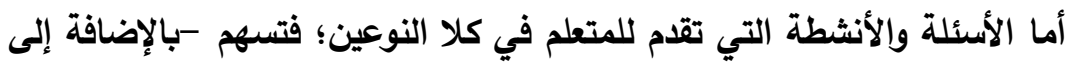

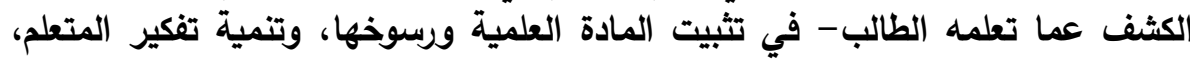

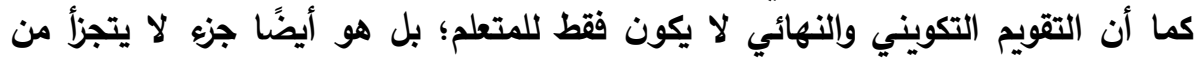

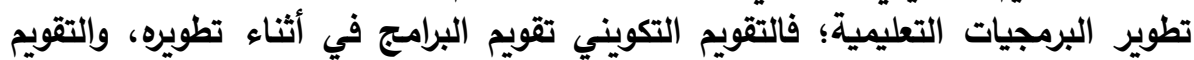

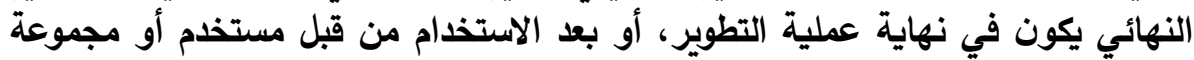

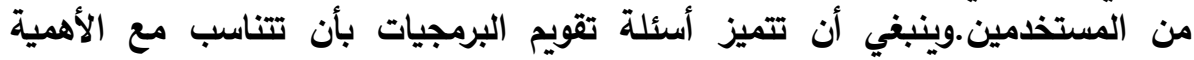

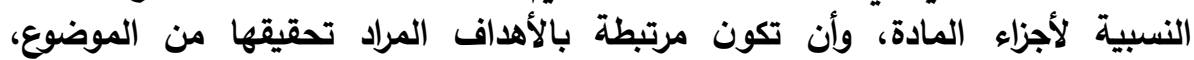

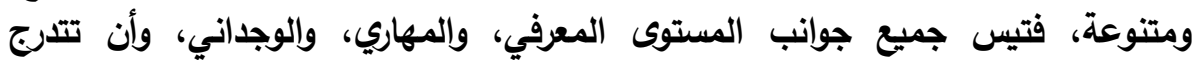

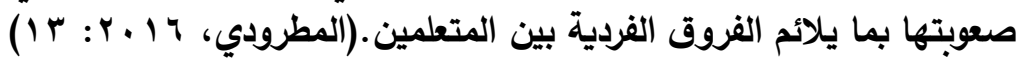

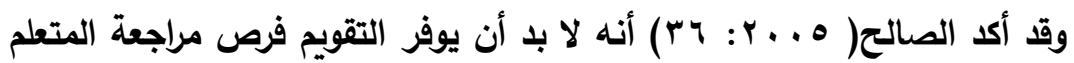
لإجاباته وتنقيحها قبل تأكيدها، وأن يتميز التقويم بالثمولية في قياس جميع أهداف التان

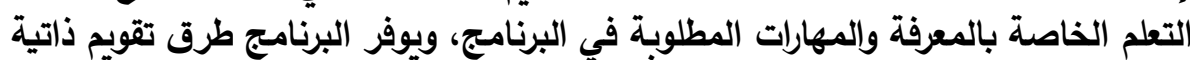
متنوعة ومتكرة؛ لتمكين المتعلم من توجيه تقدمه في الدراسة قبل الثبات التقويم النهائي.

إن أهم مواصفات البرمجيات المتعلقة بالتقويم: • ت تضمن البرمجيات نماذج تقويم تسمح للمتعلم بتقويم نفسه ذاتيًّا. • ت تضضمن البرمجية التعليمية تقويمًا مرحليًّا. • ت تضمن البرمجية التعليمية تقويمًا نهائيًا. • ترتبط أسئلة تقويم البرمجيات بالأهداف المتوقع تحقيقها من الموضوع. • تتارج درجة صعوبة أسئلة التقويم بما يلائم الفروق الفربية بين المتعلمين. • يتاسب عدد أسئلة التقويم مع الأهمية النسبية لأجزاء المادة. 


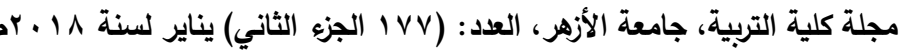
" ت تنوع أسئلة التقويم، مثل: صح وخطأ - اختيار من متعدد.

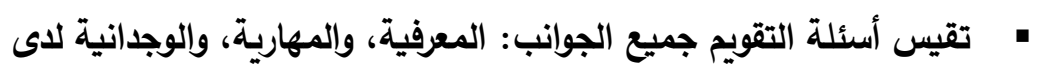

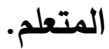

• تمكن المتعلم من مراجعة أسئلة التقويم قبل تأكيدها. • تعطي البرمجيات المتعلم الوقت الكافي لإنهاء عملية التقويم. و - توافر التغذية الراجعة:

تعد التغذية الراجعة Feedback من العناصر المؤثرة في مواصفات البرمجيات

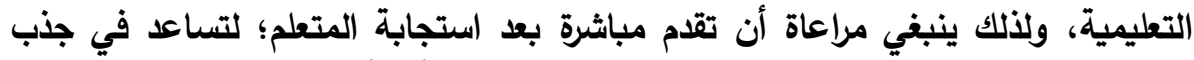

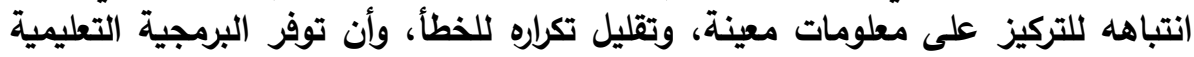

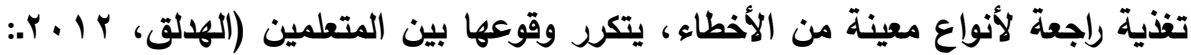

( $\varepsilon \leqslant \mu-\varepsilon r \mu$

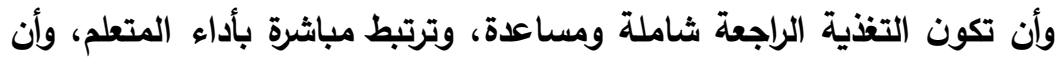

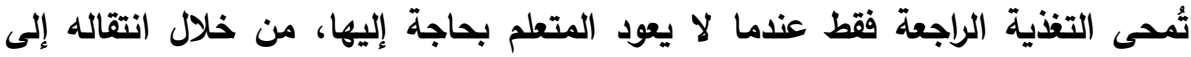

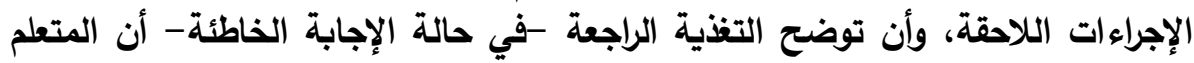

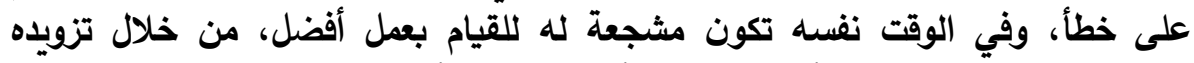

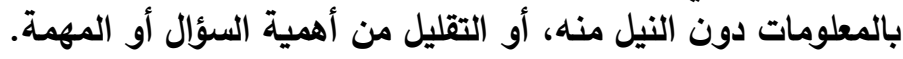
إن أهم مواصفات البرمجيات المتعلقة بالتغذية الراجعة:

• تقدم البرمجيات التغذية الراجعة المناسبة مباشرة بعد استجابة المتعلم.

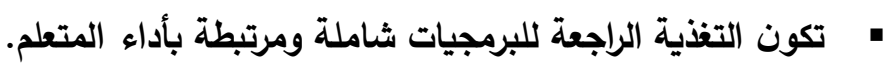
• ت تضضمن تغذية راجعة للأخطاء المتوقع تكرار حدوثها بين المتعلمين. • تسهم التغذية الراجعة في تحسين أداء المتعلم.

• تشجع التغذية الراجعة المتعلم في حال الخطأ، دون التقليل من أهمية المهمة. • تتناسب التغذية الراجعة مع طبيعة استجابة المتعلم. • تقدم البرمجية تغذية راجعة متنوعة (نصية، وسمعية، ومرئية). المبحث الثاني: الدراسات السابقة من الاراسات التي تناولت أثر استخدام الحاسوب في التحصيل الاراسي لمواد

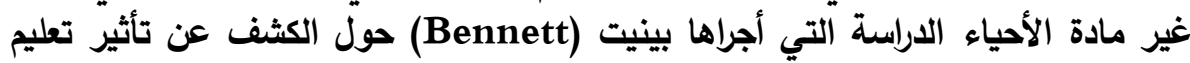


مادة الكيمياء باستخدام الحاسوب في التحصيل الدراسي والاتجاه لطلاب المرحلة الثانوية

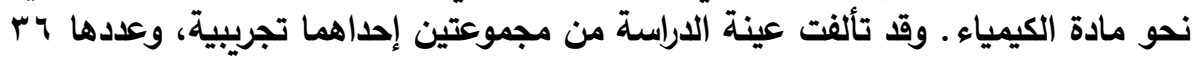

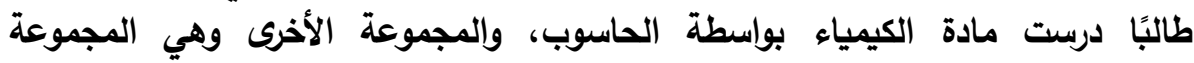

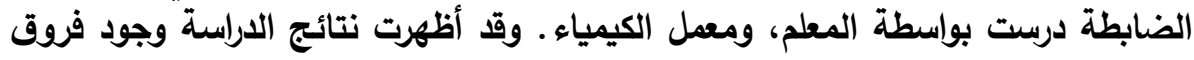

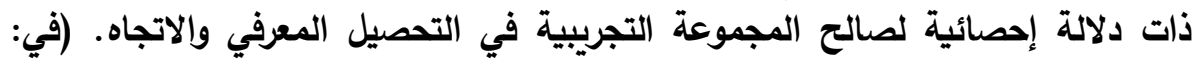

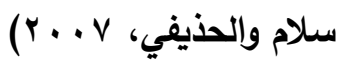

وهدفت دراسة هوانج(Huang, 2008) إلى بيان العلاقة ما بين استخدام

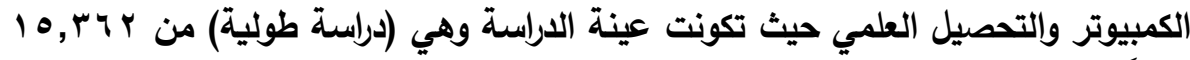

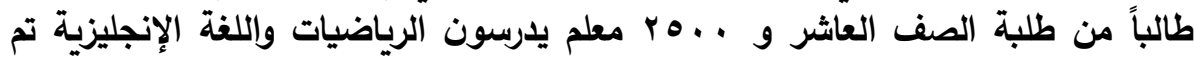

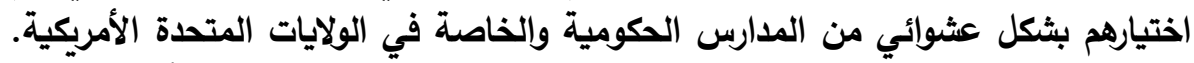

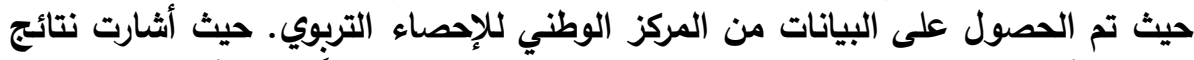

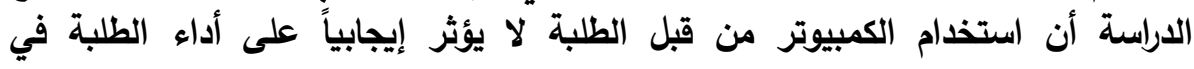

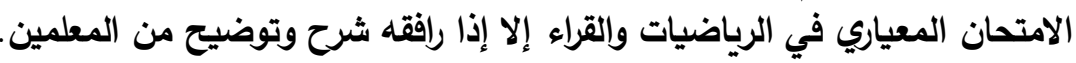

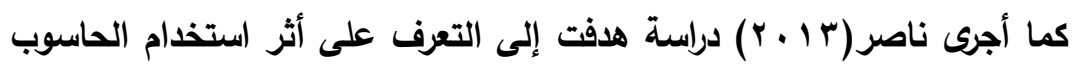

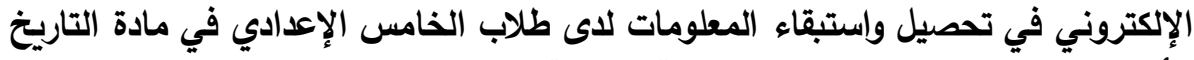

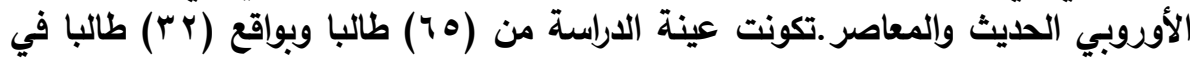

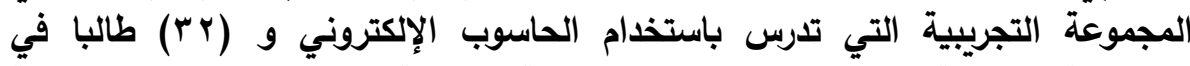

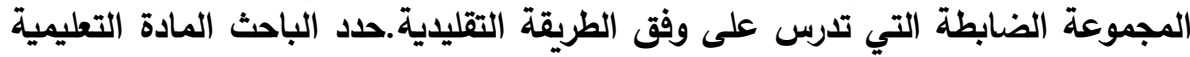

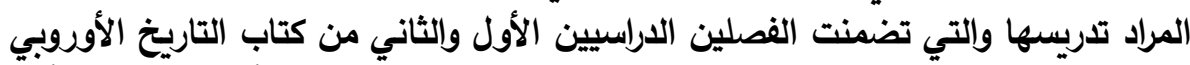

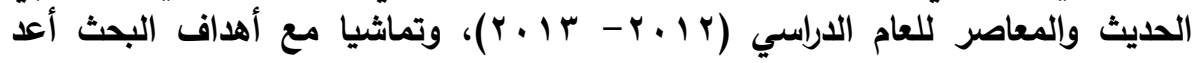

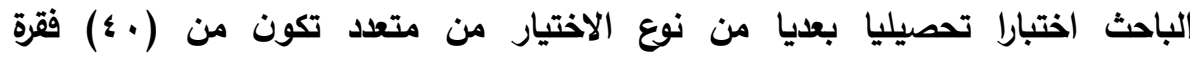

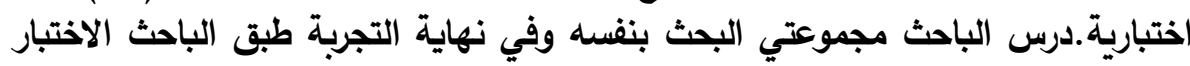

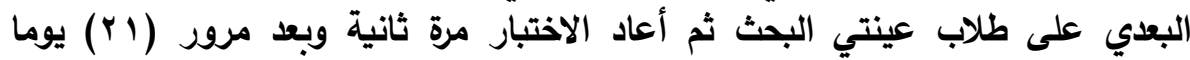

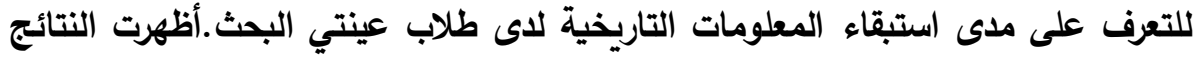

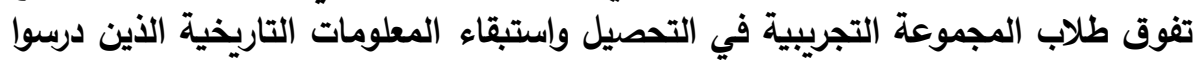

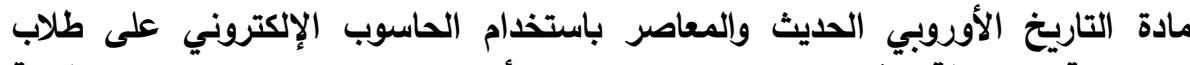

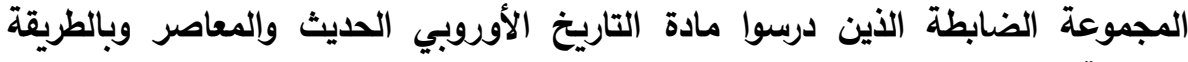

ومن الدراسات التي تناولت أثر استخدام الحاسوب في التحصيل الدراسي لمواد

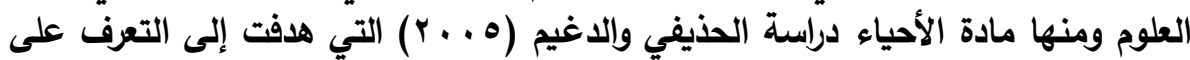

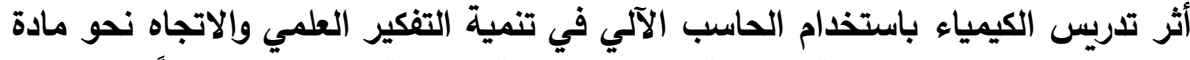

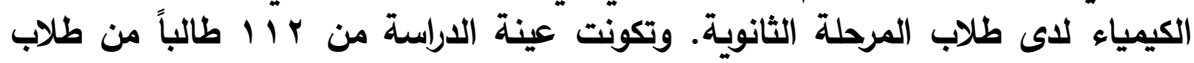




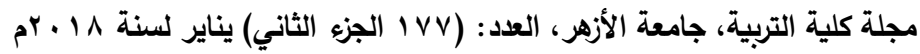

الصف الثاني الثانوي الطبيعي، موزعين على مجموعتين وبلغ عداد المجموعة التجريبية

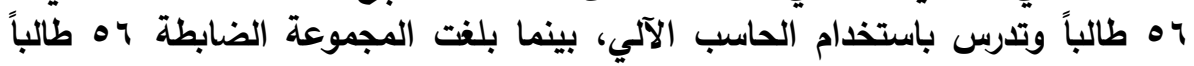

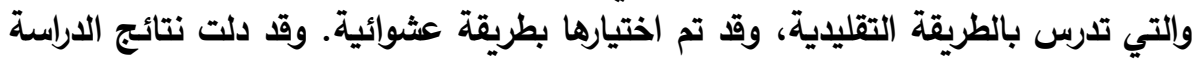

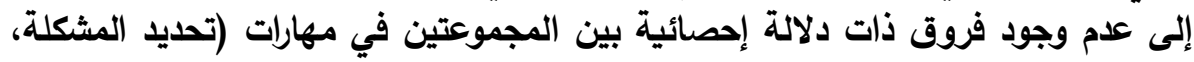

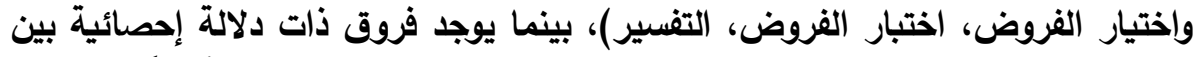

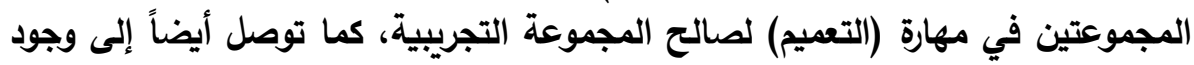

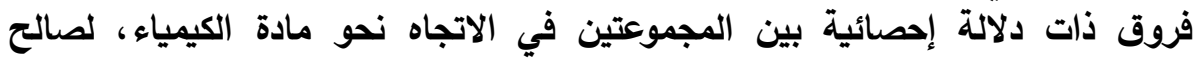
المجموعة التجريبية.

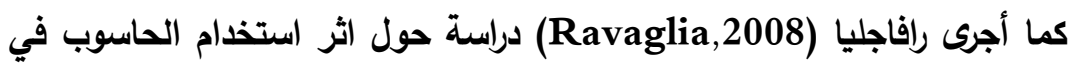

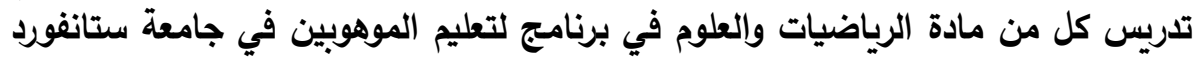

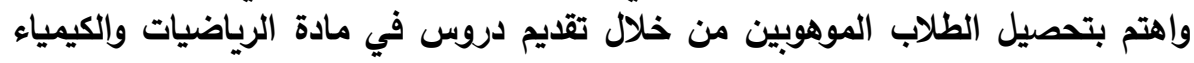

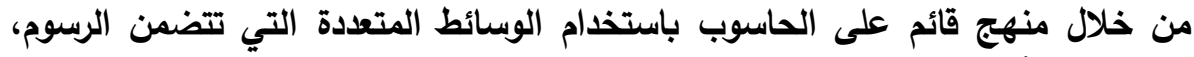

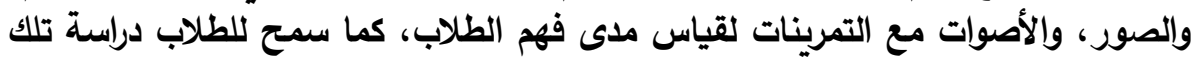

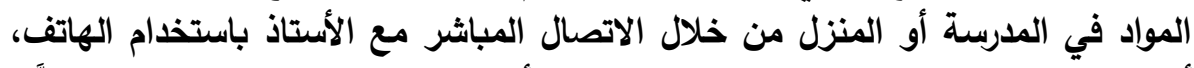

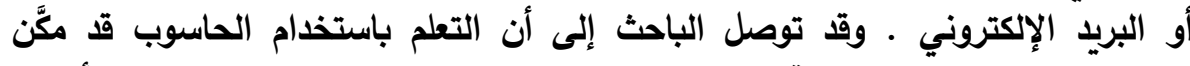

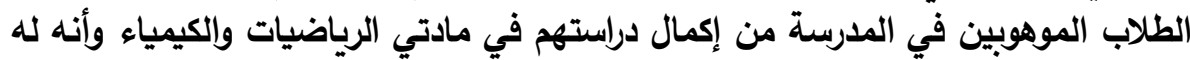
فاعلية جيدة في التعلم الأتي. أما دراسة شانج(Chang (2009) فقد هدفت إلى استقصاء أثر التعليم بمساعدة

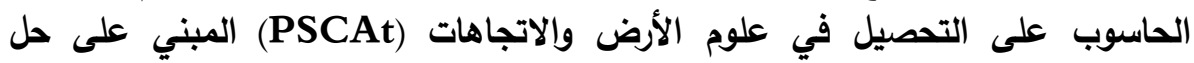

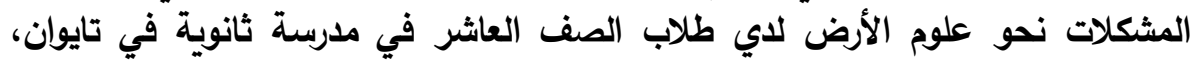

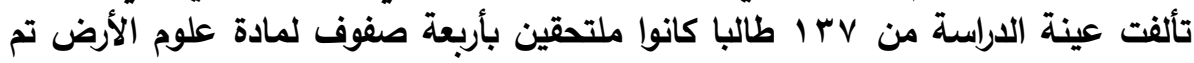

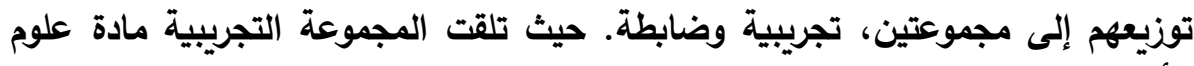

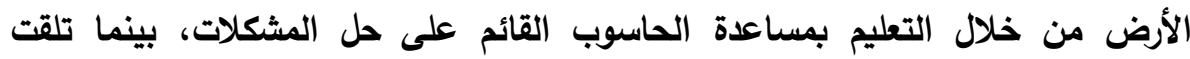

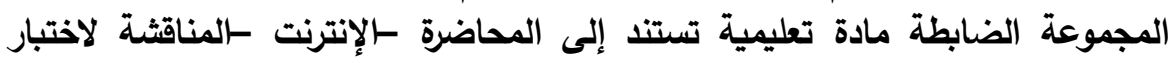

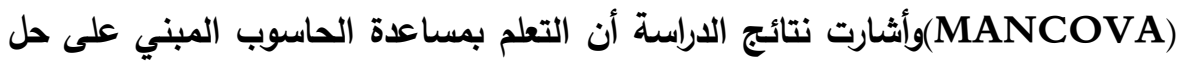

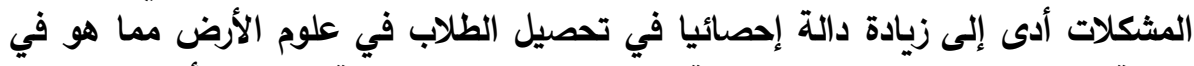

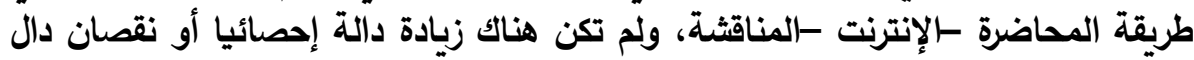
إحصائيا في اتجاهات الطلاب نحو علوم الأرض.

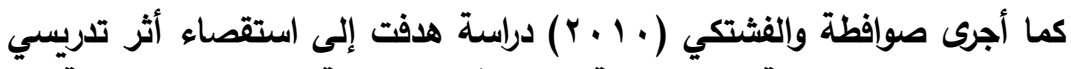

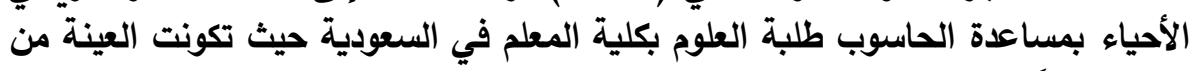

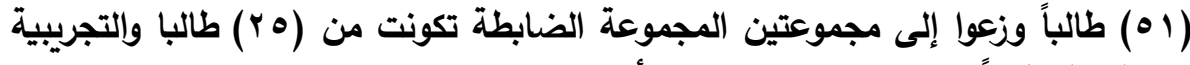

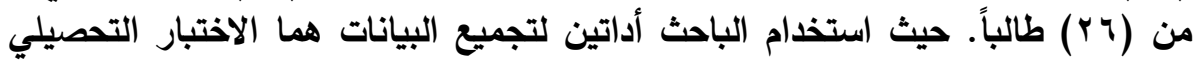




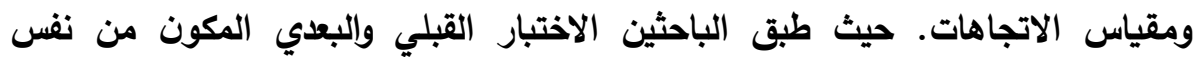

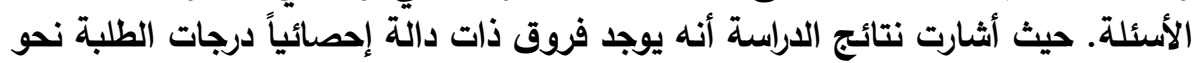
استخدام الحاسوب يعزى للمجموعة التجريبية

وفي نيجيريا أجرى كل من يوسف وأفولسبي (Yusuf \& Afolsbi, 2010)

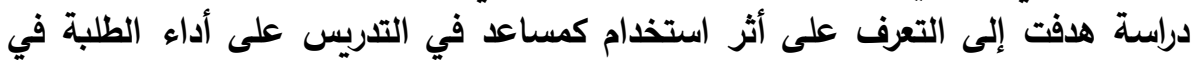

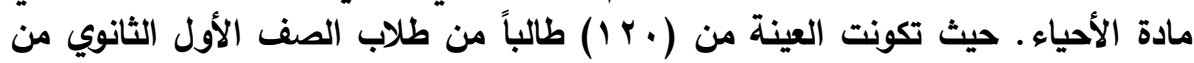

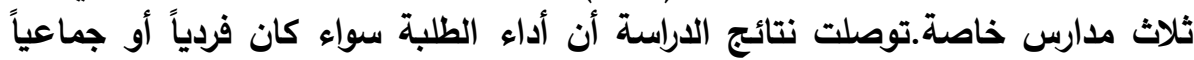

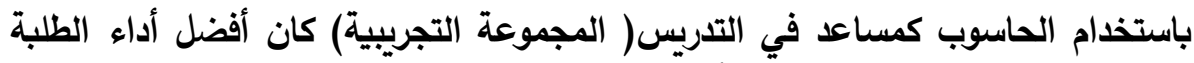

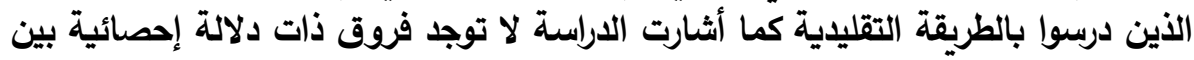

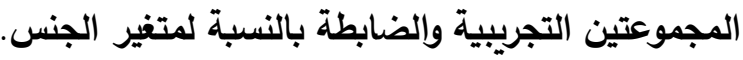

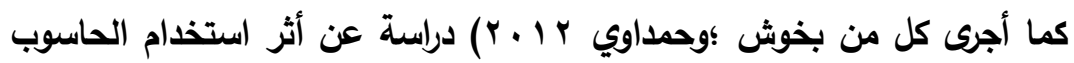

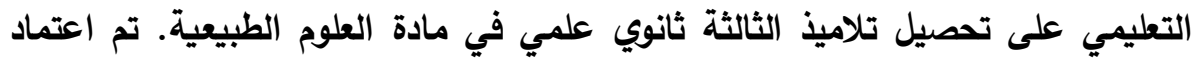

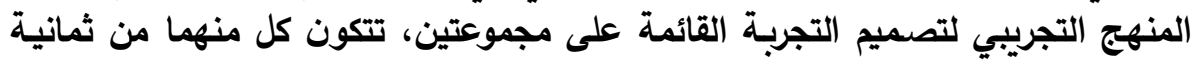

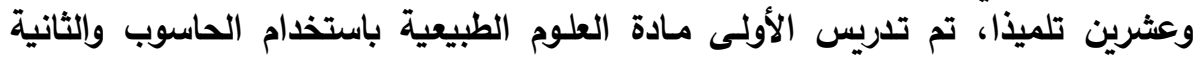

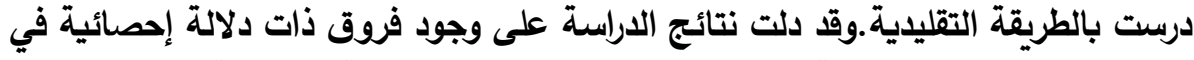
تحصيل مادة العلوم الطبيعية بين المجموعتين لصالح المالح المجموعة التجريبية.

التعقيب على الاراسات السابقة:

من خلال عرض الاراسات السابقة يظهر أن معظم الدراسات التجريبية تؤكد فاعلية

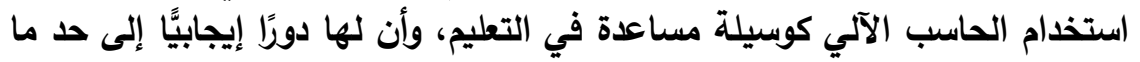

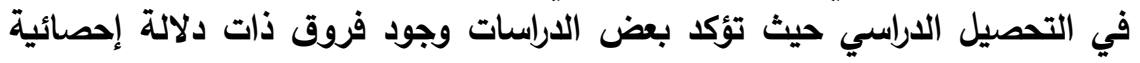

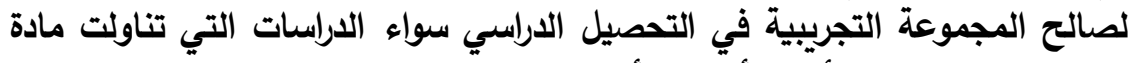
العلوم بما فيها مادة الأحياء أو مواد أخرى.

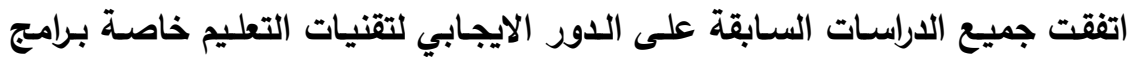

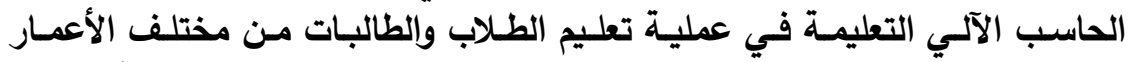

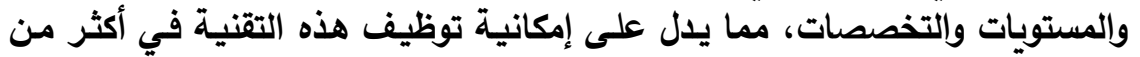




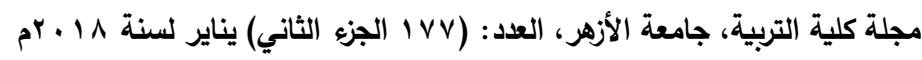

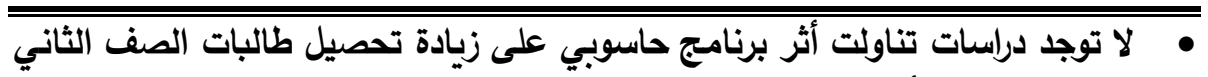

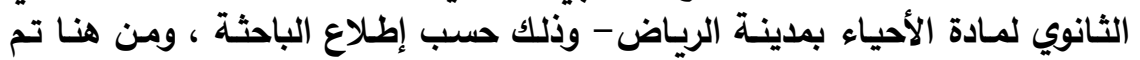

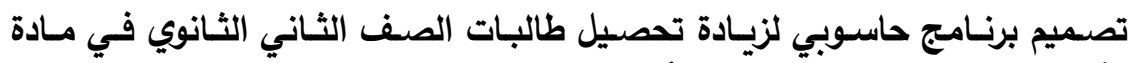

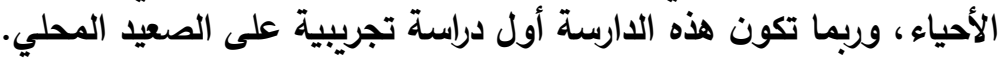

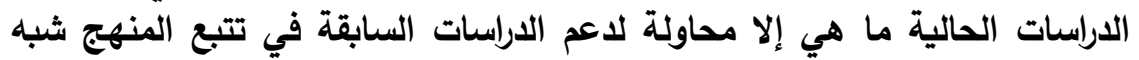

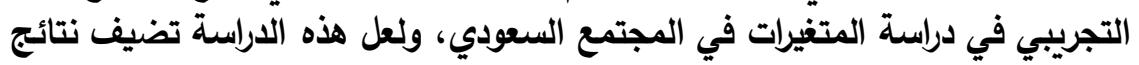

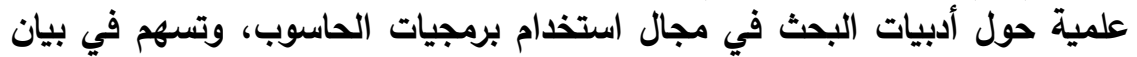

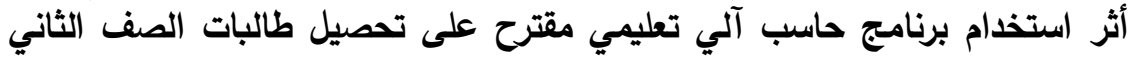

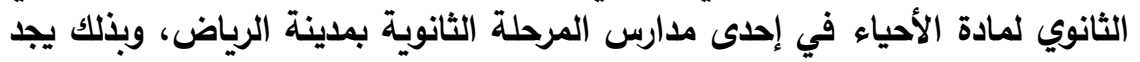

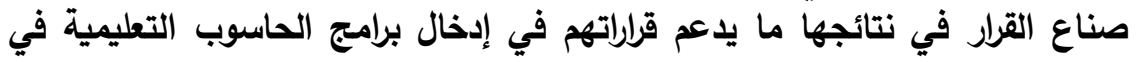

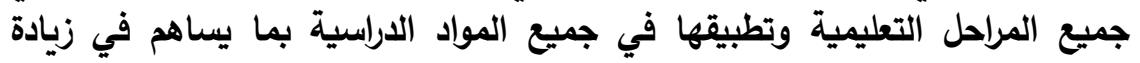

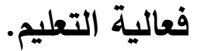

اهتمام الباحثين بثكل كبير بتصميم البرمجيات التعليمية لزيادة عملية التحصيل داخل

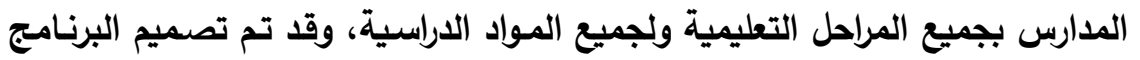

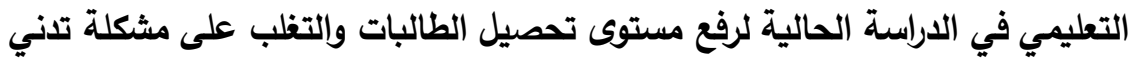
التحصيل الاراسي.

• دلت أكثر الدراسات السابقة العربية والأجنبية على وجود اهتمام من قبل الاختصاصين

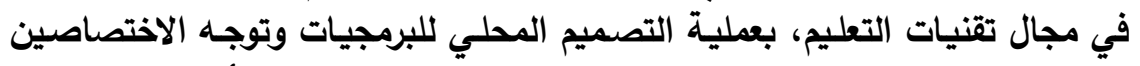
نحو تصميم البرمجيات المحلية، ممـا يعطي لهذه الاراسـة الحالية أن الحاجـة قائمـة

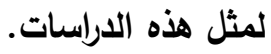

ولقد استفادة الاراسة الحالية من الدراسات السابقة في:

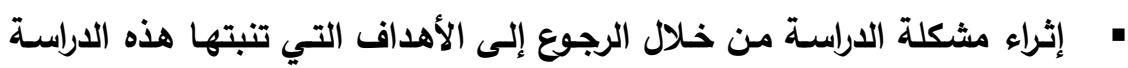

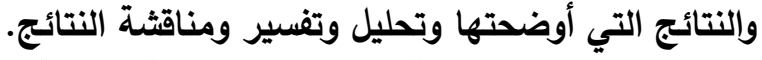

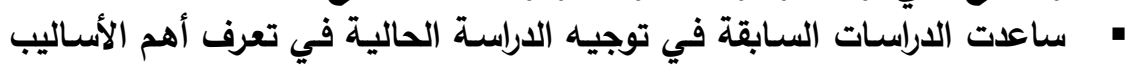

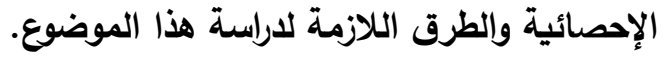

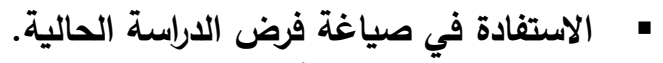

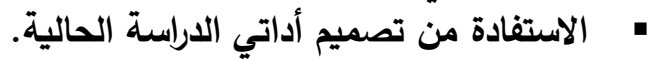
الإجراءات المنهجية للدراسة: ا أمنهج الدراسة: 
تنتمي هذه الاراسة إلى المنهج شبه التجريبي بهدف الكثف عن أثر استخدام

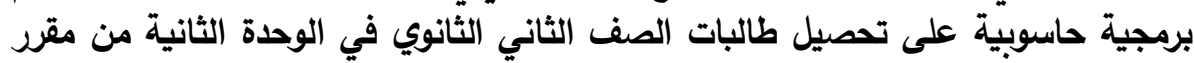
الأحياء. وهذا المنهج يتطلب اختبار مجموعتين أحدهما تجريبية تدرس مادية الأبل الأحياء

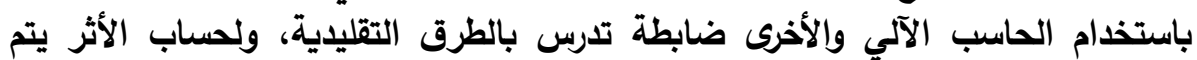

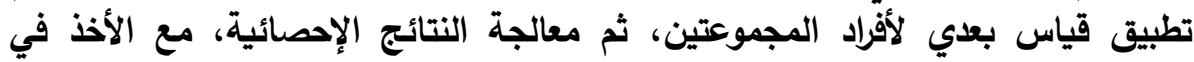

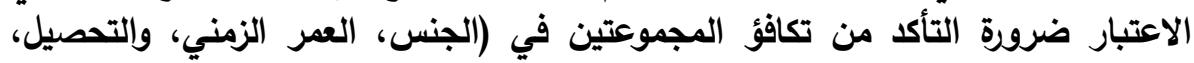
والمستوى الاقتصادي والاجتماعي).

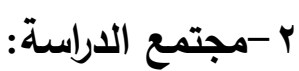
تكون مجتمع الدراسة من جميع طالبات الصف الثاني الثانوي اللاتي يدرسن

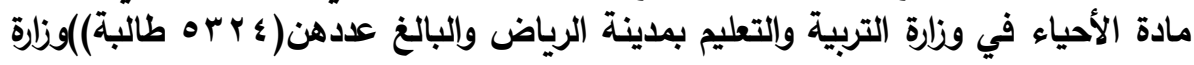

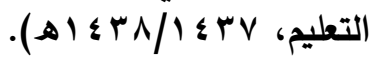

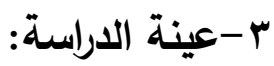

تكونت عينة الدراسة من (·) (؟) طالبة من طالبات الصف الثاني الثانوي

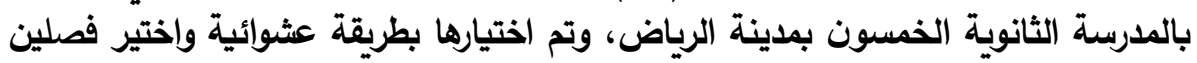

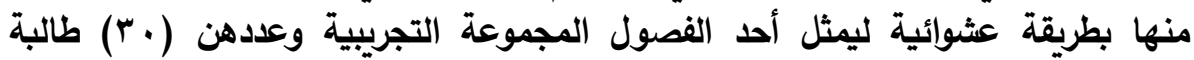

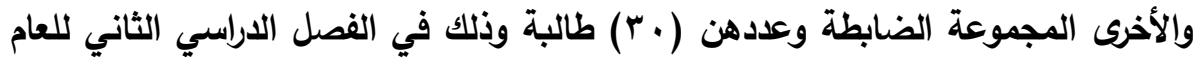

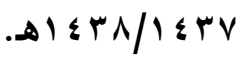

أداتا الاراسةة: - n تضمنت الاراسة الحالية أداتين رئيستين: الاختبار التحصيلي في مادة الأحياء

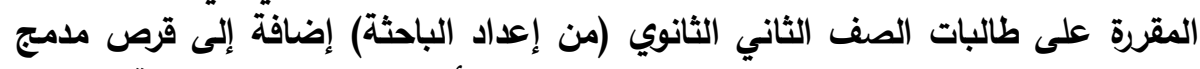

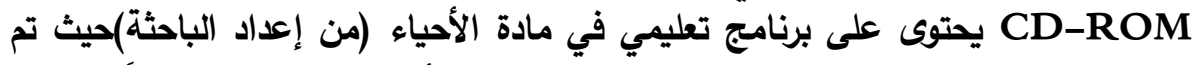

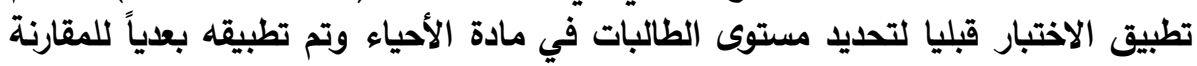
بين المجموعتين التجريبية والضابطة. الأداة الأولى: الاختبار التحصيلي تم تصميم الاختبار التحصيلي بحيث يتسم بالموضوعية ، والثبات، والصدق،

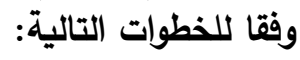




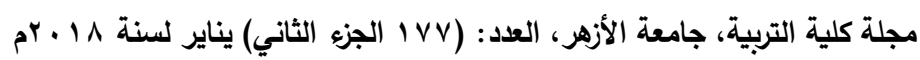

- تحليل محتوى مادة الأحياء بهاف الحصول على المفاهيم، والمبادئ والتعميمات،

$$
\text { والمهارات. }
$$

- - صياغة الأهداف السلوكية لمسادة الأحياء بثكل سلوكي قابل للملاحظة، وذلك بمشاركة معلمات المقرر والمشرفات التربويات. - - تحديد نسبة تركيز محتوى الاروس المحددة. وفي ضوء ذلك تم صياغة أسئلة الاختبار. تقنين الاختبار التحصيلي:

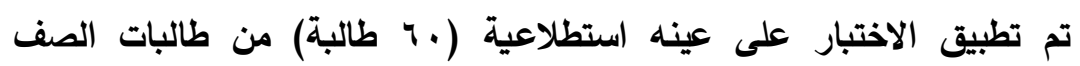

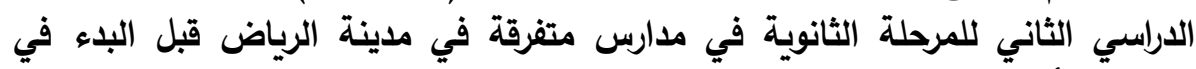

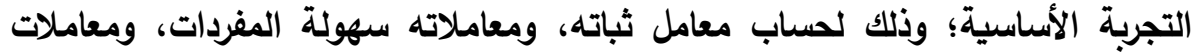
تمييزها، ومعاملات ارتباطها. وقد مرت عملية تقنين الاختبار التحصيلي بالخطوات التالية:

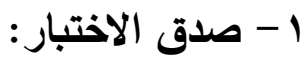
تم استخدام صدق المحكمين في هذا الصدد، حيث وافقت مجموعة الإدة المحكمين

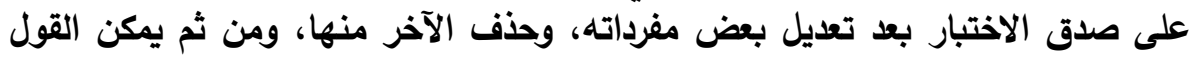

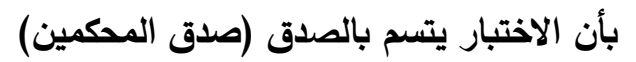

$$
\text { r }
$$

تم حساب معاملات تمييز مفردات الاختبار الحالي، وقد كان متوسط معامل

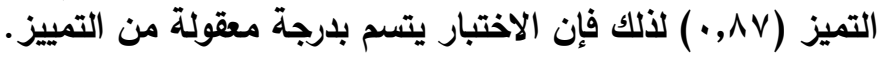
r- حساب معاملات سهولة ووضوح مفردات الاختبار: تم حساب معاملات سهولة مفردات الاختبار، وكان متوسط معامل السهولة

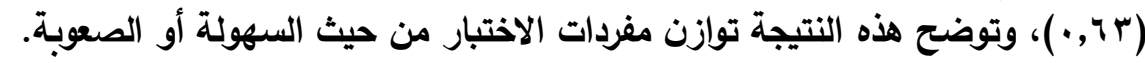
ع - حساب معاملات الاتساق الاخلي بين مفردات الاختبار 
أيضاً تم حساب معامل الارتباط (صدق الاتساق الاخلي)، ولقد كان متوسط الاخل

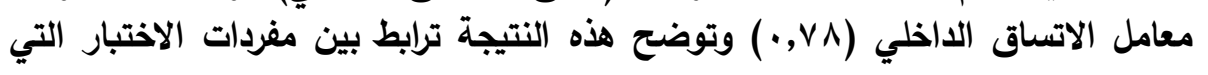
يتضمنها المحور.

$$
\text { 0 - حساب معامل ثبات الاختبار : }
$$

تم حساب ثبات الاختبار المستخدم في الدراسة الحالية بطريقة كودر

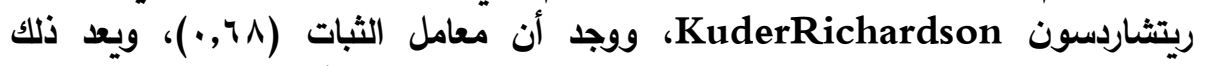
المعامل مقبولاً في ضوء المعامل طبيعة الدراسة وأهدافها، وأيضاً ثبات التجزئة النصفية التهات (TV)

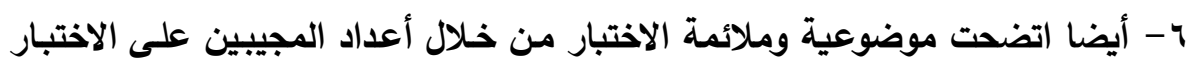

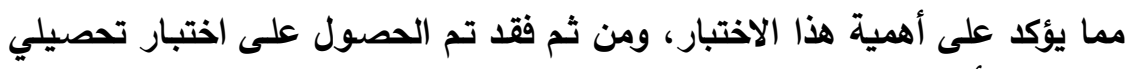

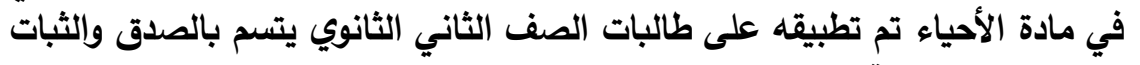
في صورته النهائية.

الأداة الثانية: البرمجية التعليمية الحاسوبية لمادة الأحياء في الصف الثاني الثانوي (إعداد الباحثة). إعداد البرنامج: تـم إعداد البرنـامج الحاسـوبي في ضـوء عـد مسن الخطوات، وفـق النمـوذج

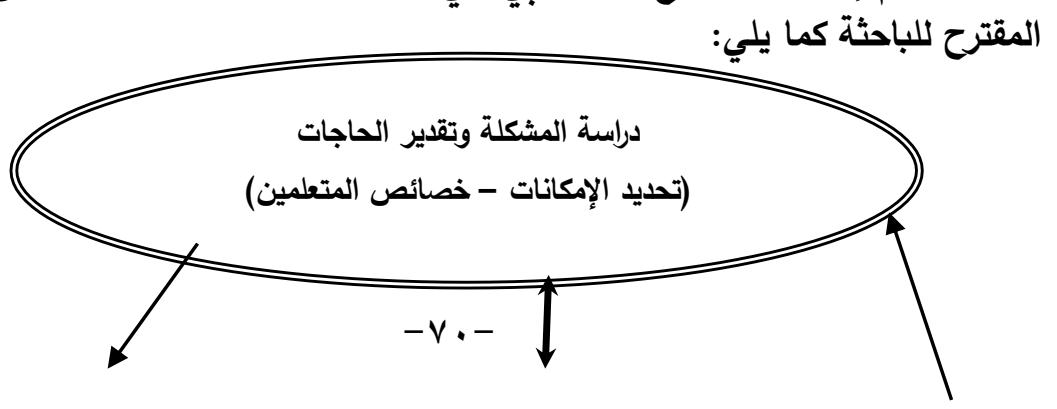




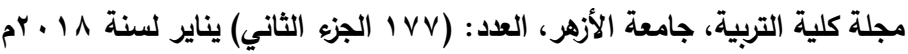

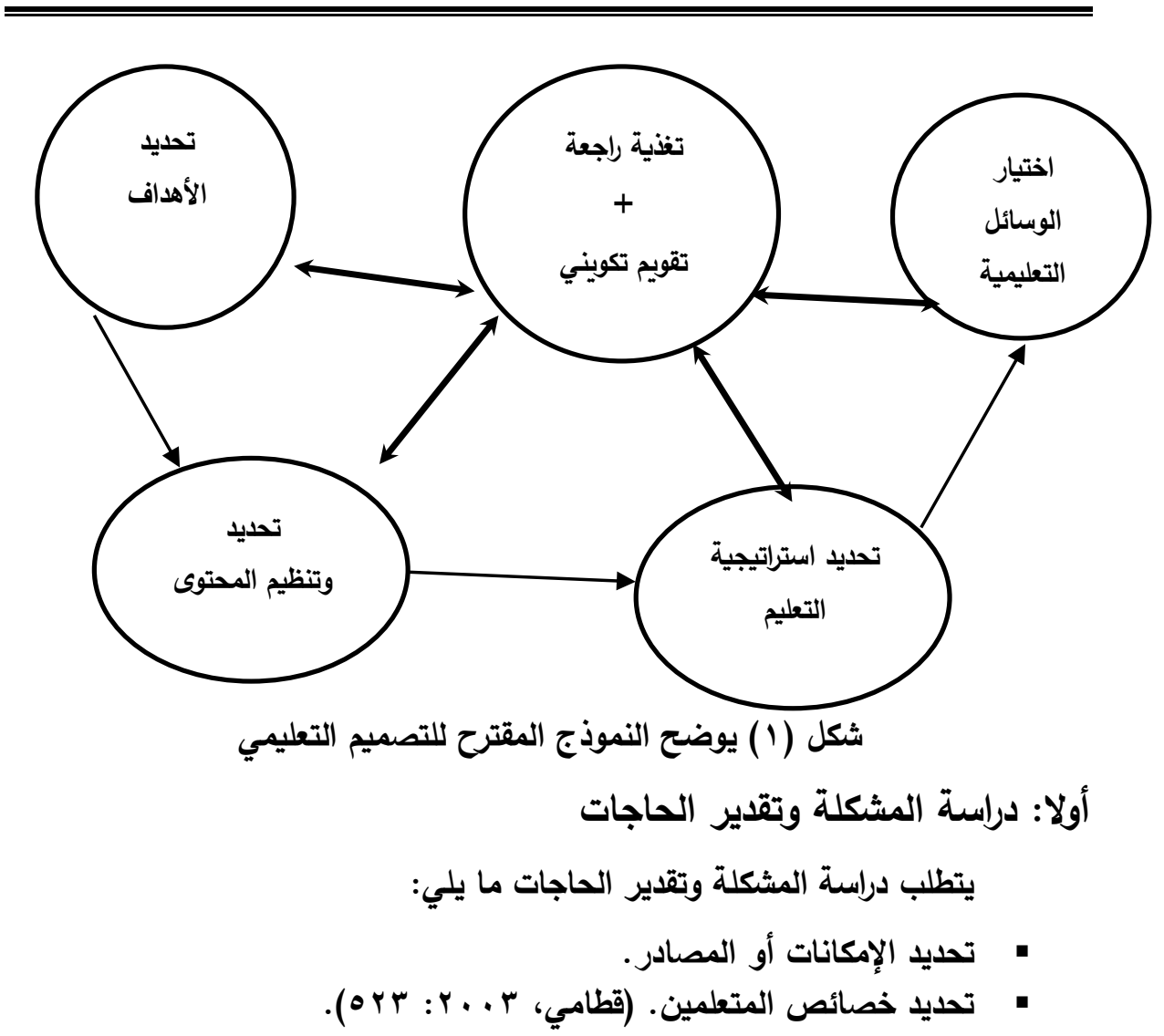

ثانياً: تحديد الأهداف العامة:

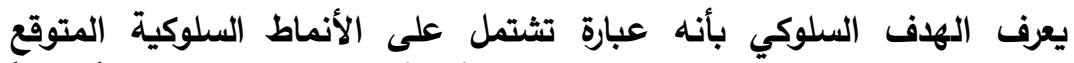

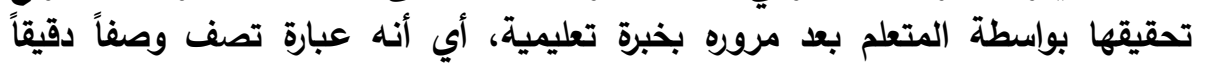

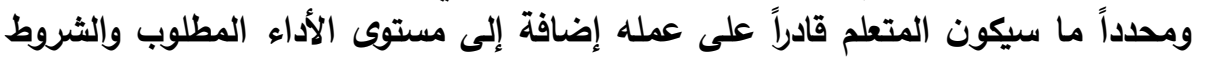

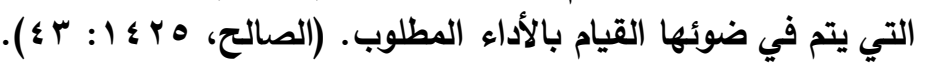
ثالثا-تحديد وتنظيم المحتوى:

في ضوء الأهداف التي سبق تحديدها، يتم إعداد المحتوى في ضوء المباء المنظور

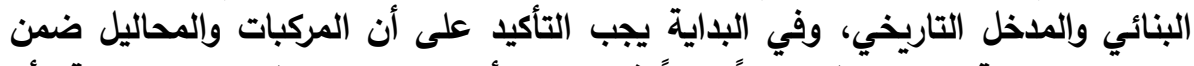
المفاهيم العلمية التي تحتّل موقعاً هاماً في تعلم الأحياء سواء داخل حجرة الدارية، أو الوائ 
خلال تصاميم البرامج التعليمية، ولقد ساد اهتمام عالمي بأفكار الطلاب المتعلقة بالظواهر الطبيعية التي يتم تعلمها في الأحياء ـ وللمدخل التاريخي في تدريس التهائ الأحياء نزعتان:

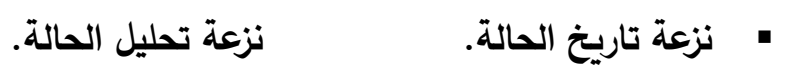

ويسعى تدريس الأحياء إلى تنمية الطلاب ويقصد به الإحساس والوعي بأهمية العلم ودوره

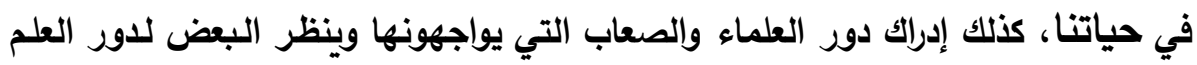

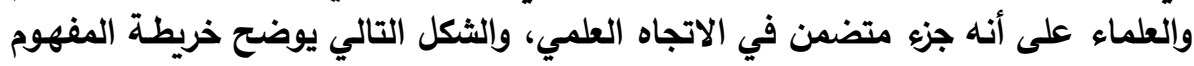

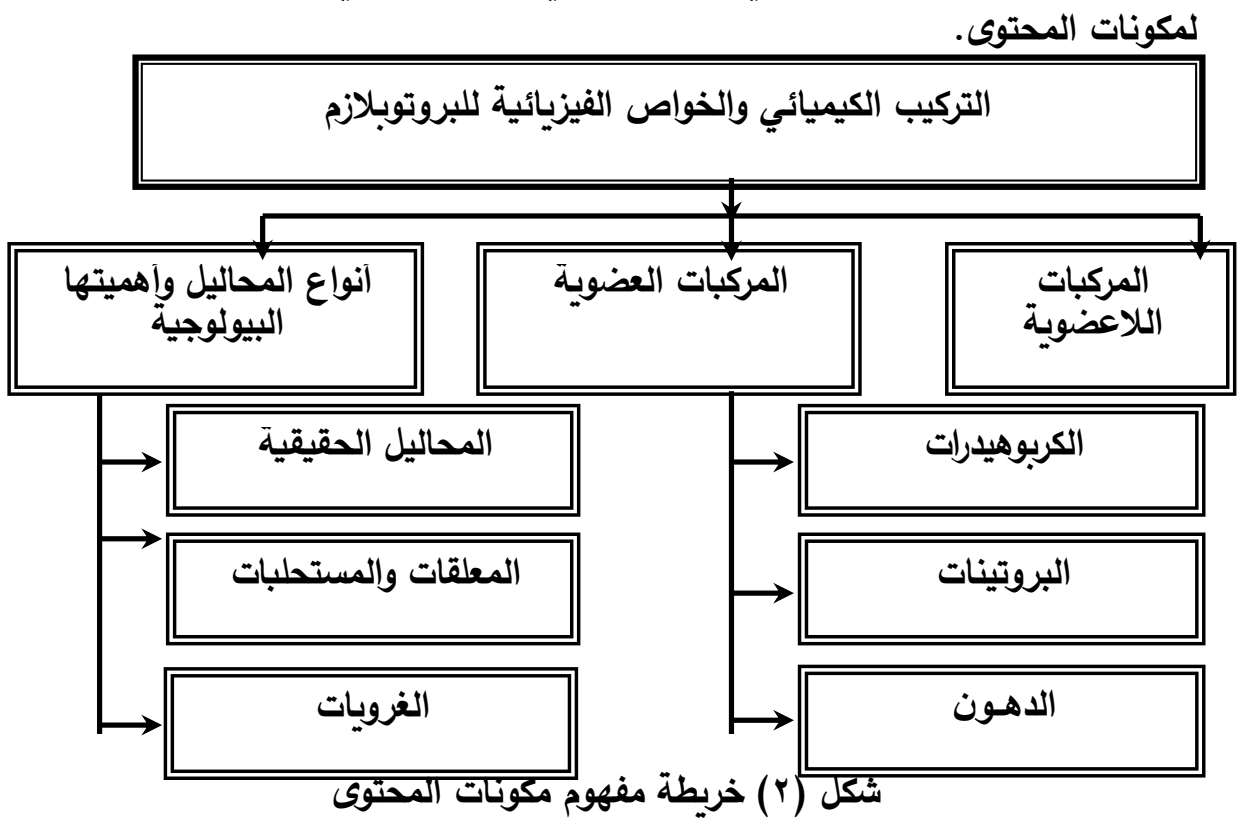

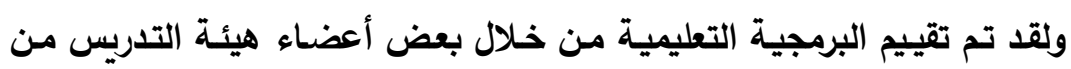

جامعة الملك سعود كما هو موضح بالجدول التالي:

جدول (1) تقييم البرمجية التعليمية

\begin{tabular}{|c|c|c|c|c|}
\hline المحكمين & تقدير & أقل تقدير & متوسط تقدير & عناصر التقييم \\
\hline 1. & $1 \ldots$ & $V \leqslant, 00$ & $91, \vee \wedge$ & خصائص المحتوى \\
\hline 1. & $1 \ldots$ & 79 & $\wedge q, r \wedge$ & خصائص استخدام المتعلم \\
\hline 1. & $1 \ldots$ & $\Lambda$. & 9 qY,Yo & خصائص تشغيل البرنامج \\
\hline
\end{tabular}




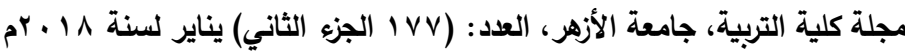

\begin{tabular}{|c|c|c|c|c|}
\hline 1. & $1 \ldots$ & $V r, 1$. & $q 1, r r$ & الدرجة الكلية للتقييم \\
\hline 0 & $1 \ldots$ & ^o & $9 \leqslant, \leqslant$. & التقدير بالنسبة المئوية \\
\hline
\end{tabular}

" حساب المتوسطات من . .

رابعاً: تحديد الاستراتيجيات التعليمية:

تم تطبيق الاستراتيجيات التعليمية التي يتضمنها نموذج فرجينيا جونسون

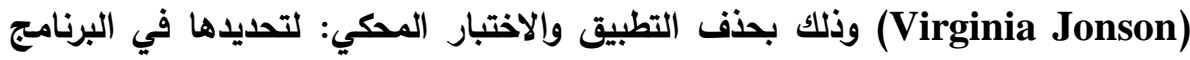

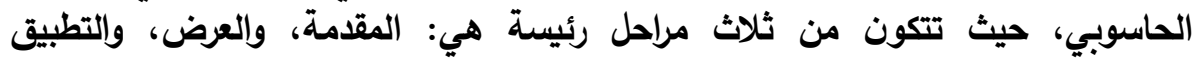

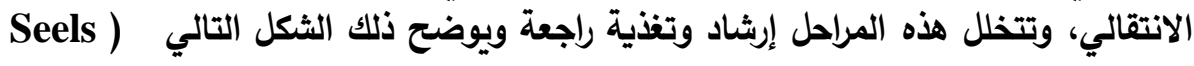

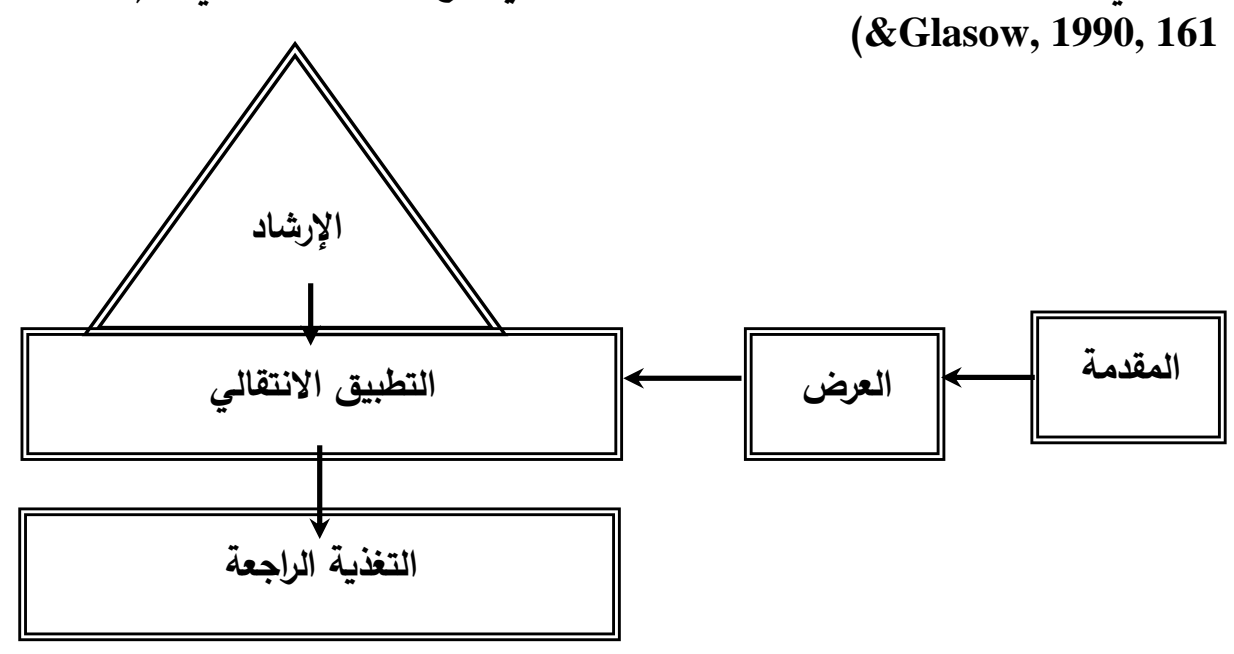

شكل (r) نموذج فرجينيا جونسون

وفيما يلي تناول تلك الاستراتيجيات على النحو التالي:

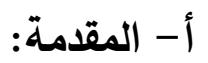

تتضمن المقدمة التالي:

• تحديد عنوان الوحدة بثكل قصير.

• عرض الأهداف العامة.

• توضـيح تعليمـات طريقـة اســخدام البرنــامج الحاسـوبي، لمســاعدة الطالبـة فـي

التحكم بالبرنامج بيسر وسيمهولة. 


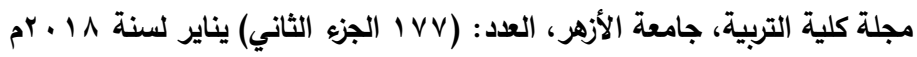

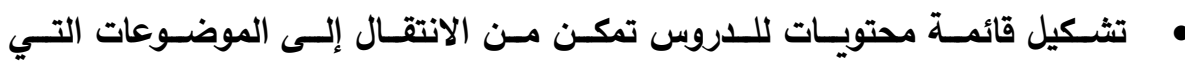

تفضلها في البرنامج الحاسوبي. محتوبات

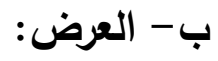

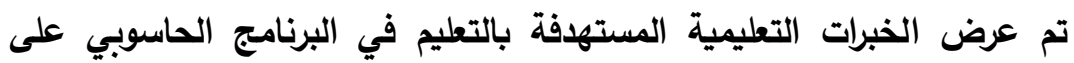

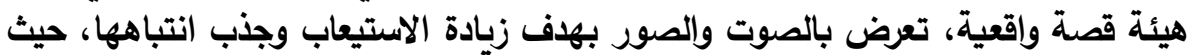

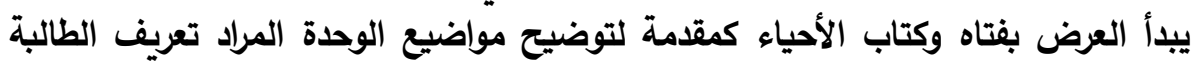

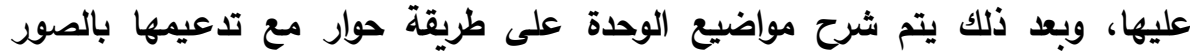

$$
\text { ج- الموضحة في البرمجية. }
$$

تم ترتيب الموضوعات في البرنامج الحاسوبي من الأسهل إلى الأصعب، حيث الموفي

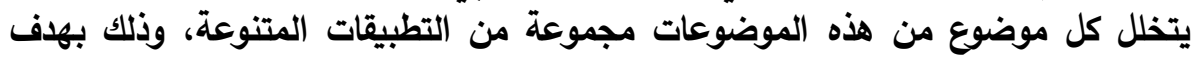

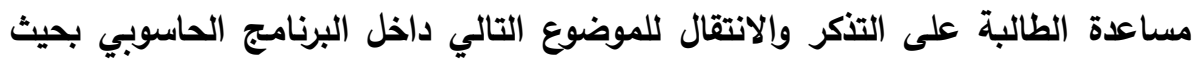
تجيب الطالبة على كل تطبيق يلي الجزء الخاص بله مباشرة بعد دراستها لله.

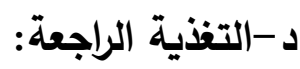

$$
\text { تم تحديد وتوزيع التغذية الراجعة لتعزيز تعلم الطالبة على النحو التالي: }
$$

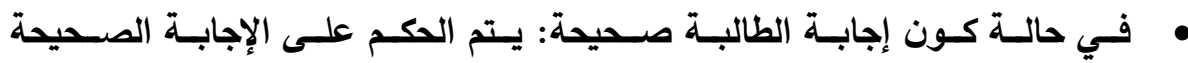

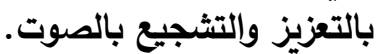

• في حالـة كـون إجابـة الطالبـة خاطئة: يـتم الحكم على الإجابـة الخاطئسة بإصــار صوت يوحي لها بأن الإجابة خاطئة.

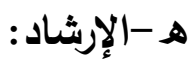

تم وضع مجموعة من التعليمات التي تساعد على التحكم بالبرنامج الحاسوبي

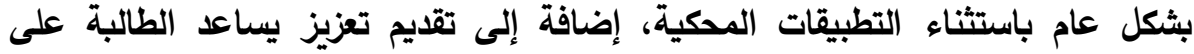

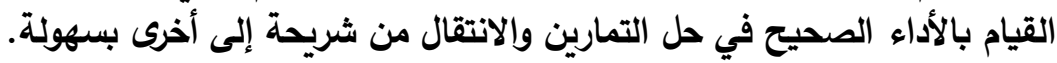
خامسا: الخطوات الإجرائية المنظمة لاختيار تقنيات التعليم: -أسس اختيار التقنية التعليمية:

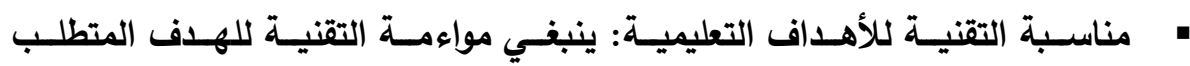
التحقيق. مناسبة 


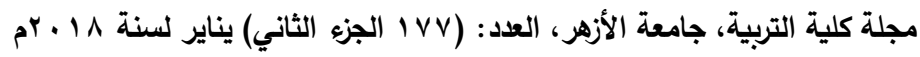

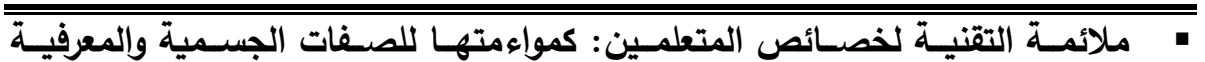

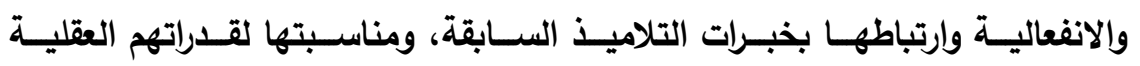

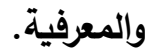

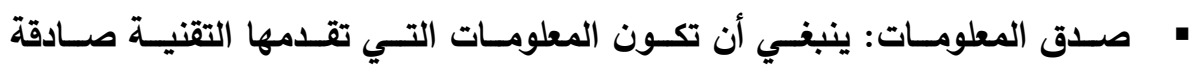
ومطابقة للواقع، وأن تعطي صورة متكاملة عن الموضوع.

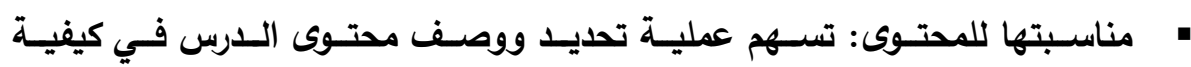

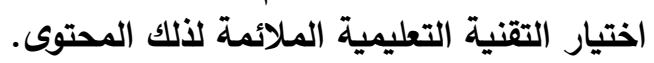

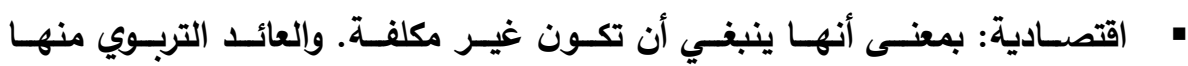

مناسب لتكلفتها.

• إمكانيـة اسـتخدامها مـرات متعـدةة : يجب أن تتميـز التقنيـة بإمكانيـة اسـتخدامها

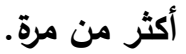

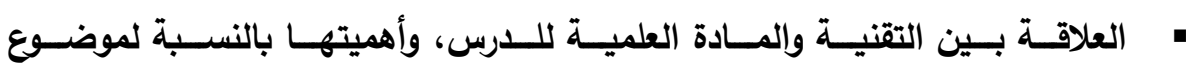

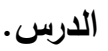
• مدى توفر عنصر الإثارة والتشويق في الوسيلة نفسها. (التودري، ب . . ب).

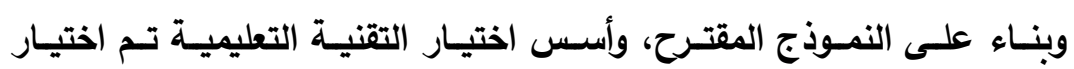
تقنية البرمجية التعليمية التي تستخدم لجذب التباه الطالبات لعملية التعليم.

-الأدوات التي سوف تستخدم لهذا البرنامج:

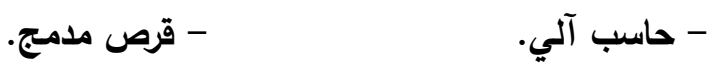

وعند تصميم البرمجية التعليمية تم مراعاة القواعد التالية:

ا - التأكد على تصميم البرمجية وفق أسلوب النظم:

r - قواعد قبل استخدام البرمجية التعليمية:

• تحديد جهاز الحاسب الآلي المناسب.

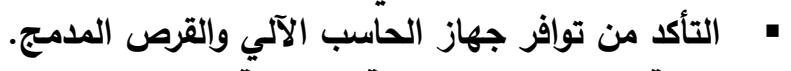

• تهيئة مكان عرض البرمجة التعليمية.

ب- قواعد عند استخدام البرمجية التعليمية: 


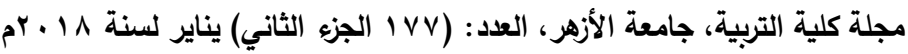

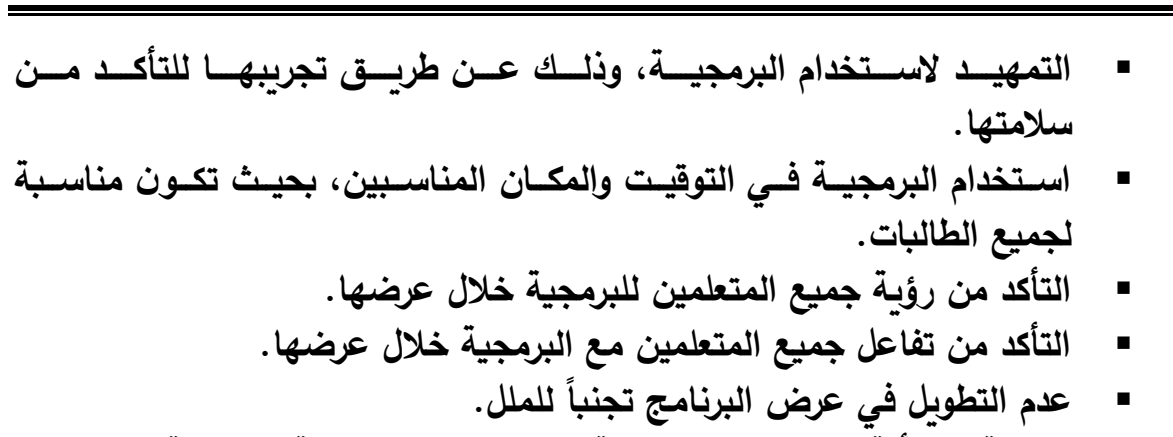
• الإجابة عن أية استفسارات ضرورية للمتعلم حول البرمجية التعليمية.

ـ - قواعد بعد الانتهاء من استخدام البرمجية:

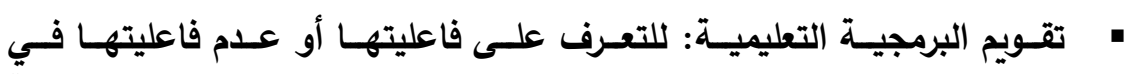

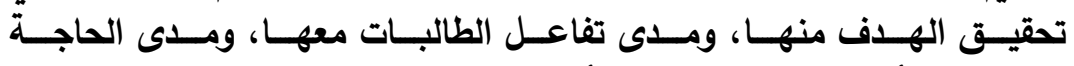

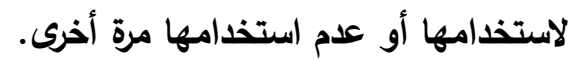

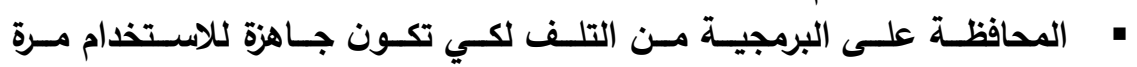

أخرى.

• حفـظ البرمجيـة التعليميـة: أي وضـعها فـي مكــان مناسـب يحـافظ عليهـا

لحين استخدامها مرة أخرى.

سادساً: التقويم:

إن الهاف الرئيسي للتقويم هو التأكد من مدى تحقيق البرمجية التعليمية

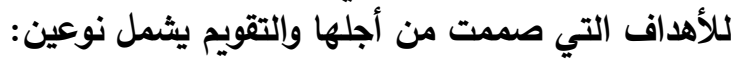

1 - التقويم التكويني:

وهو إخضاع البرمجية للتقويم أثناء تطويرها، ويتضمن التقويم التكويني مراحل

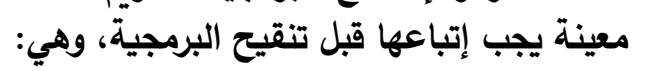

أ-مرحلة المراجعة الاخلية:

تم عرض محتوى البرمجية التعليمية على مختصين (محكمين) في مادة الأحياء

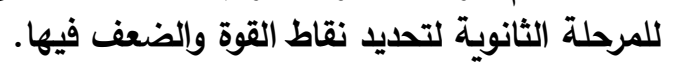

$-v^{4}-$ 


\section{ب-مرحلة التجريب:}

وتعني استخدام البرمجية لمدة ثلاثة أسابيع على فصلين من طلبات الصف الصفاء

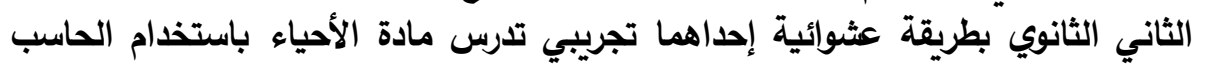

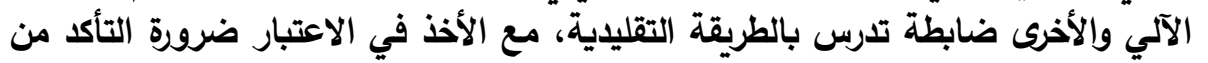

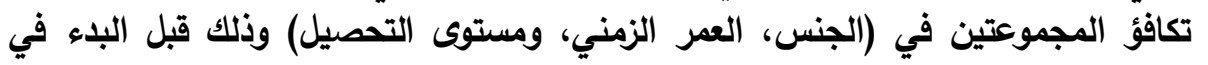
التجربة.

r - الاختبارات محكية المرجع:

وتثمل الاختبار عند تطبيقه قبلياً ويهدف إلى مدى اكتساب الطالبة للمفاهيم

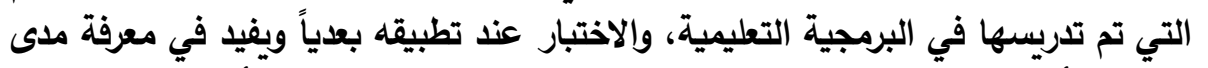

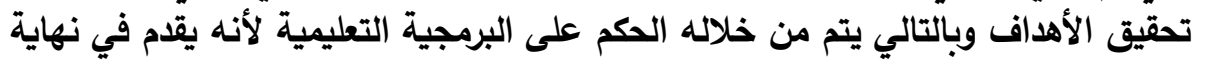

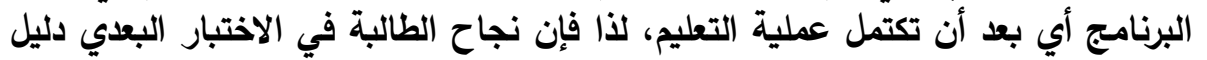
على التأثير الإجمالي للبرمجية التعليمية التي تم تصميمها. سابعاً: تطبيق أدوات الدراسة:

استخلم في الدراسة الحالية التصميم القائم على نظام المجموعتين إحداهما

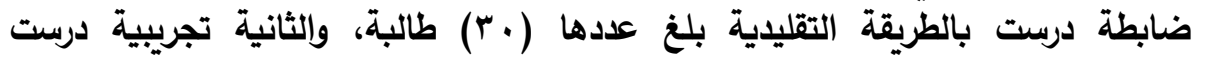

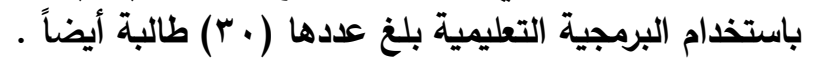

وتم التحقق من تكافؤ المجموعتين في العمر الزمني، والمستوى الاقتصادي

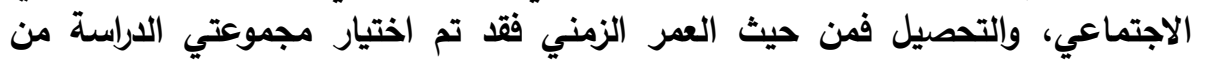

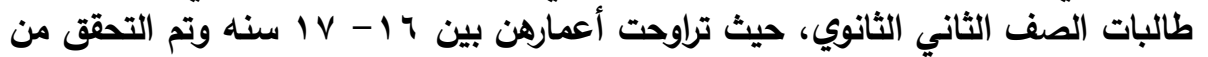

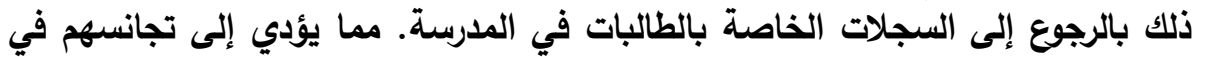

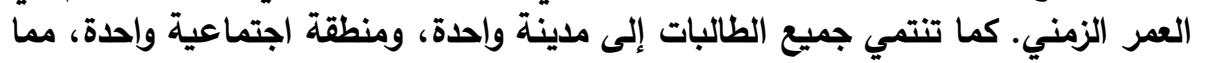
يثير إلى تقارب المستوى الاقتصادي والاجتماعي.

ومن حيث تجانس المجموعتين في التحصيل، تمت معالجة النتائج إحصائياً في

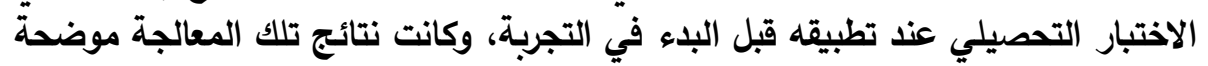

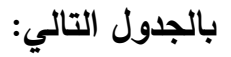

جدول (r)

نتائج اختبار ت لمعالجة نتائج طالبات المجموعتين التجرببية والضابطة

عند تطبيق الاختبار التحصيلي قبلياً 


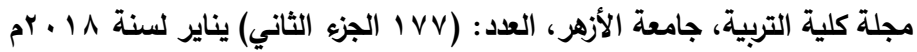

\begin{tabular}{|c|c|c|c|c|c|c|c|c|}
\hline \multirow[b]{2}{*}{ التعليق } & \multirow{2}{*}{ الدلالة } & \multicolumn{2}{|c|}{ قيمة ت } & \multirow{2}{*}{ المعياري } & \multirow{2}{*}{ الحسابي * المتوسط } & \multirow[b]{2}{*}{ العدد } & \multirow[b]{2}{*}{ المجموعات } & \multirow[b]{2}{*}{ التطبيق } \\
\hline & & |الجدولية & المحسو & & & & & \\
\hline \multirow{2}{*}{ غير دالة } & \multirow{2}{*}{$\cdot, \cdot 1$} & \multirow{2}{*}{ ץ, ד } & \multirow{2}{*}{$\cdot, \cdot 7$} & r, ro & $11,1$. & $r$. & التجريبية & \multirow{2}{*}{ القبلي } \\
\hline & & & & $r, r V$ & $11,1 \mu$ & $\mu$. & الضابطة & \\
\hline
\end{tabular}

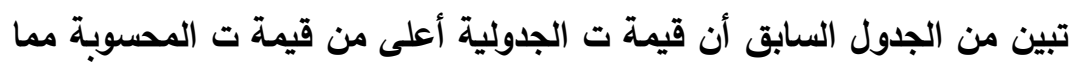

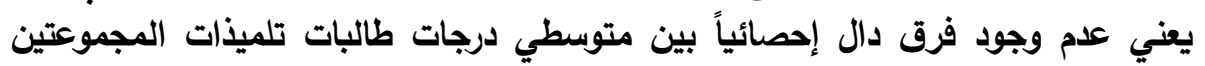

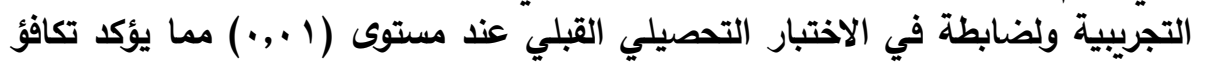
المجموعتين التجريبية والضابطة في الإئية التحصيل الديطيل الدراسي. ثامناً: المعالجة الإحصائية للنتائج

استخدمت الأساليب الإحصائية التالية: 1- - المتوسط الحسابي للمجموعتين. r- الانحراف المعياري للمجموعتين لمعرفه البعد عن المتوسط. r- معامـل التميـز والســهولة لمعرفـة مسدى سـهولة وصـعوبة أسـئلة الاختبـار التحصيلي.

؛ - معامل ثبات كودر ريتشارسون Kuder Richardson لمعرفة مدى ثبات الإنيات أسئلة الاختبار التحصيلي ومناسبتها لأغراض الدراستة ه- معامل ارتباط بيرسون لحساب صدق الاتساق الداخلي لمعرفة مدى صدق أسئلة الاختبار التحصيلي. عرض نتائج الاراسة ومناقشتها وتحليلها وتفسيرها: بعد تطبيق الدراسة وإجراء الاختبار البعدي عولجت البيانات إحصائياً لتخرج

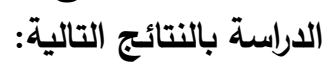
للإجابة عن سؤال الاراسة الحالية والأي نصه "ما أثر استخدام برنامج

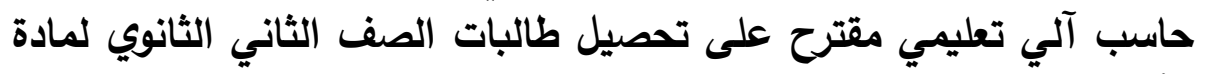
الأحياء بمدينة الرياض؟ العليف معتج 


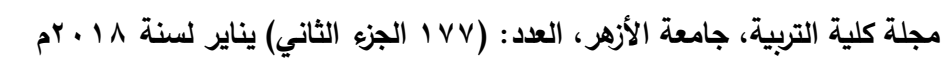

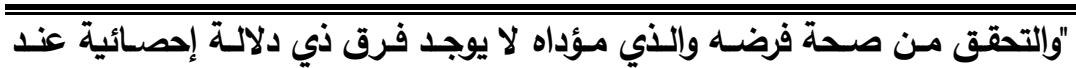

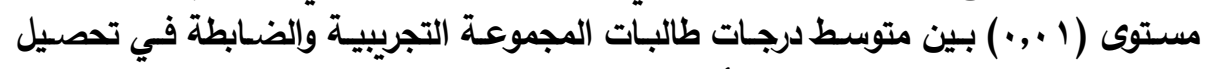

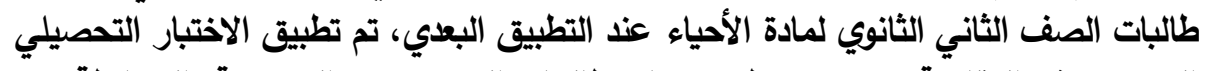

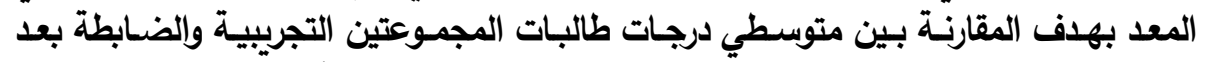

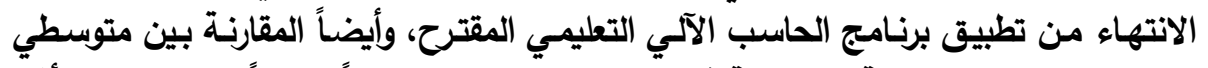

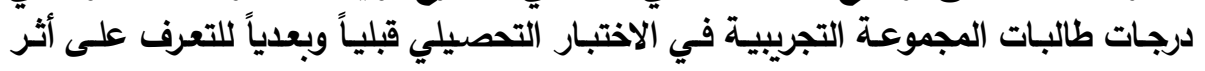

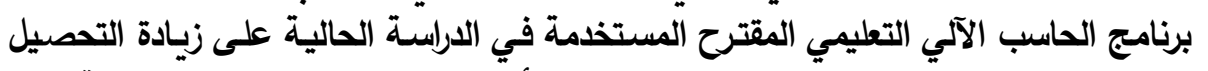

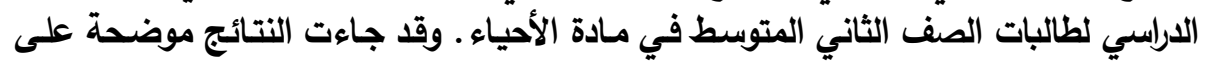

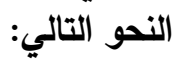

جدول (r)

نتائج اختبار ت لمعالجة نتائج طالبات المجموعتين التجرببية والضابطة عند تطبيق الاختبار التحصيلي بعدياً

\begin{tabular}{|c|c|c|c|c|c|c|c|c|}
\hline \multirow{2}{*}{ التعليق } & \multirow{2}{*}{ الدلالة } & \multicolumn{2}{|c|}{ قيمه ت } & \multirow{2}{*}{ المعياري } & \multirow{2}{*}{ الحسابي * المتوسط } & \multirow{2}{*}{ | العدد | } & \multirow{2}{*}{ المجموعات } & \multirow{2}{*}{ لتطبيق } \\
\hline & & لجدولية & المحسوبـة & & & & & \\
\hline \multirow{2}{*}{ دالة عند } & \multirow{2}{*}{$\cdot, \cdot 1$} & \multirow{2}{*}{ ץ, } & \multirow{2}{*}{$\varepsilon, \mu q$} & $1, V r$ & 17,74 & $r$. & التجريبية & \multirow{2}{*}{ البعدي } \\
\hline & & & & $r, \varepsilon r$ & $I \leqslant, Y V$ & $\mu$. & الضابطة & \\
\hline
\end{tabular}

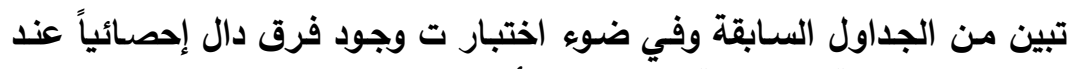

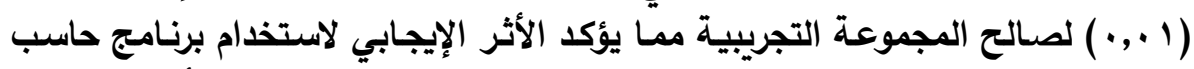

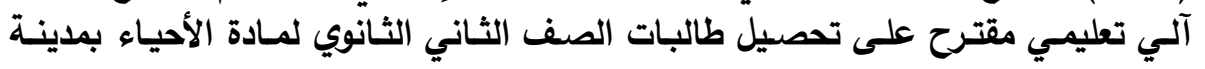
الرياض

أمسا لمعرفة فاعلية البرمجية المستخدمة في تدريس مـادة الأحياء على زيـادة

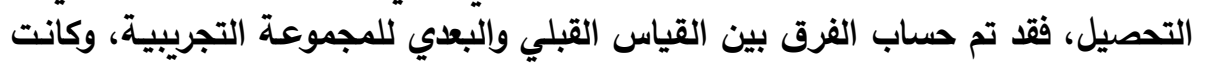
النتائج موضحة بالجدول تمل حلتياب الترقين

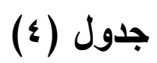

اختبار (ت) لدلالة الفروق بين متوسط الاختبار قبلي

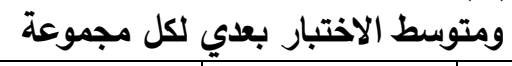

\begin{tabular}{|c|c|c|c|c|c|}
\hline التعليق & مستوى | & قيمة ت & بعدي & قبلي & المجموعة \\
\hline
\end{tabular}




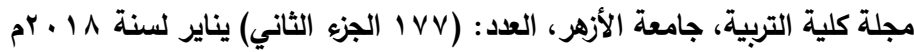

\begin{tabular}{|c|c|c|c|c|c|c|c|c|}
\hline & الدلالة & |الجدولية & لمحسوبة & الانعراف & الحسابي * المتوسط & المعياري & لالحسابي " المتوسط & \\
\hline دالة عستوى & $\cdot, \cdot 1$ & $Y, V \circ T$ & $1 \cdot, \leqslant r$ & $1, V r$ & r 17, & r, & $11,1$. & التجريبية \\
\hline دالة عستوى & $\cdot, \cdot 1$ & $r, V \circ \neg$ & $\wedge, \ldots$ & $Y, \leqslant Y$ & $I \leqslant, Y V$ & $r, r V$ & $11,1 \pi$ & الضجابطة \\
\hline
\end{tabular}

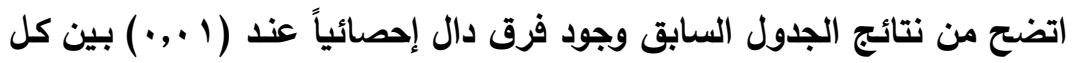

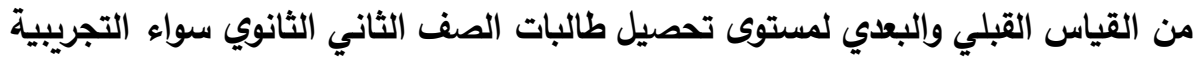

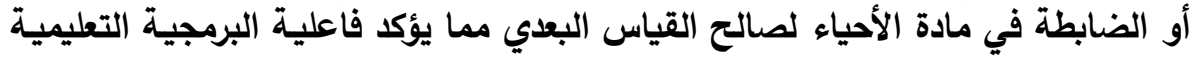

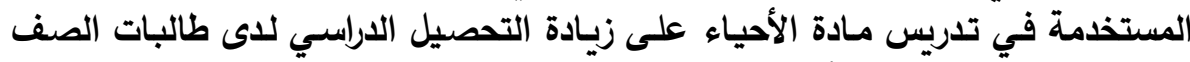

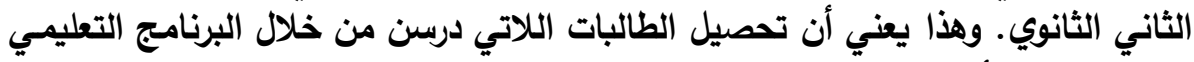

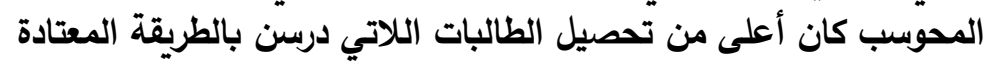

ولعل هذه النتيجة تعزى لما يمتاز به البرنامج التعليمي المحوسب من مزيا كائ كان

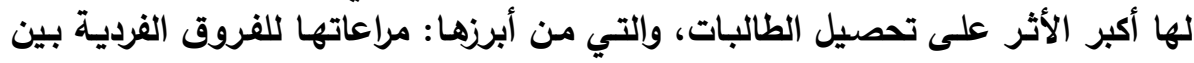

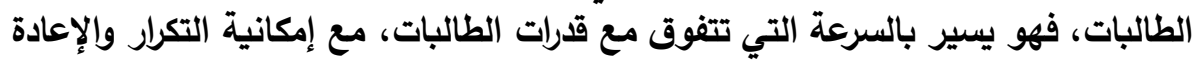

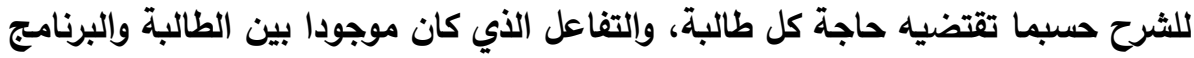

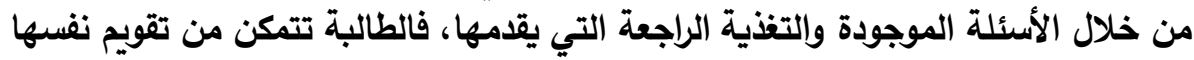

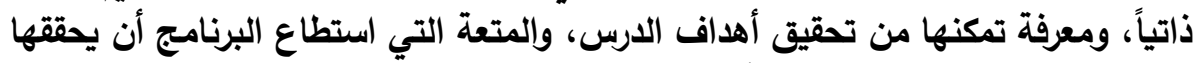

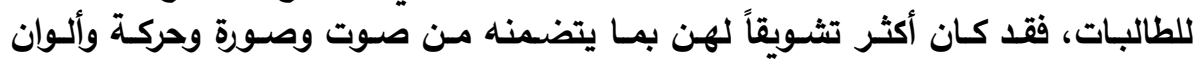

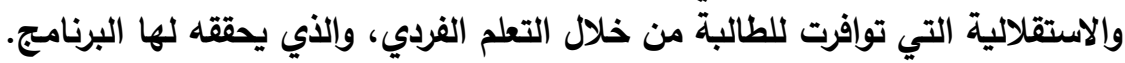

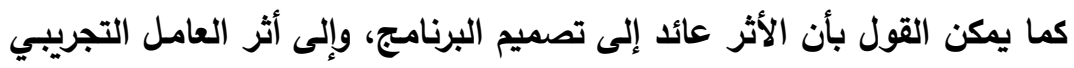

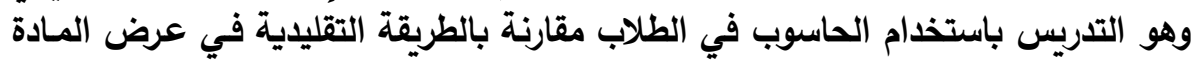

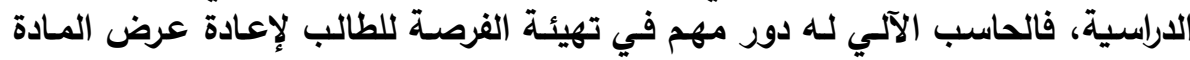

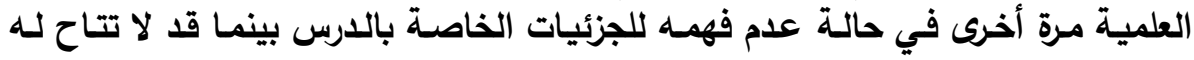

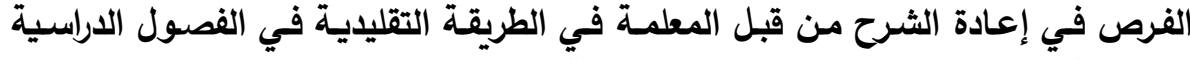

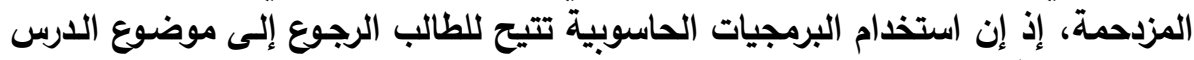

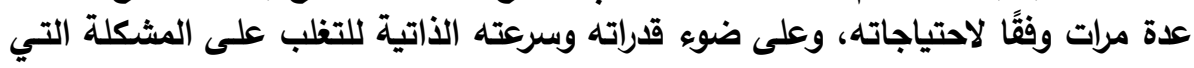




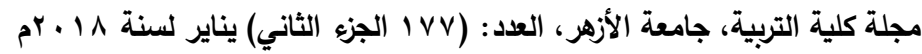

تواجهه في مادة الدرس من خلال حل التمارين، وتلقي التغذية الراجعة، وإعادة المحاولية في حالة الأستجابة الخاطئة.

وقد يعود تفوق الحاسوب في زيادة التحصيل في مادة الأحياء إلى:

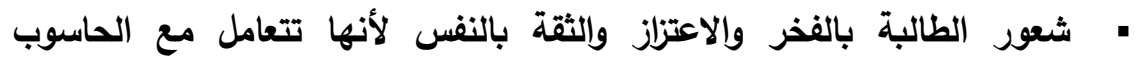

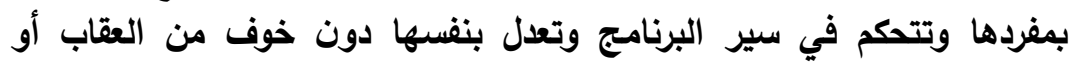

الانتقاد أمام بقية الطالبات، وهذا يزيد في رغبة ولئة الطالبة في التعليم

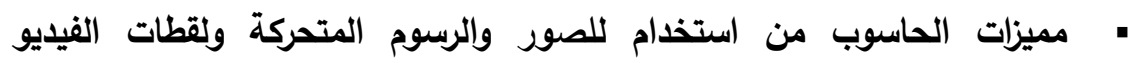

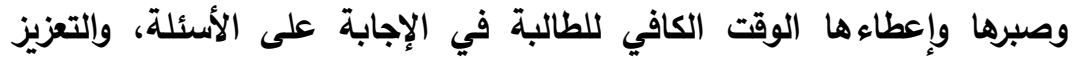

المستمر الأي يتبع كل إجابة صحيحة واعيرها

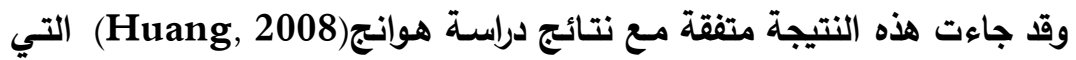

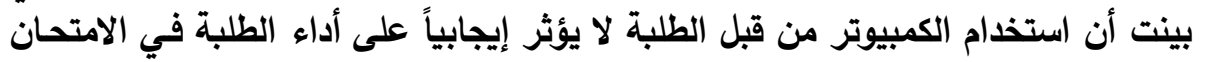

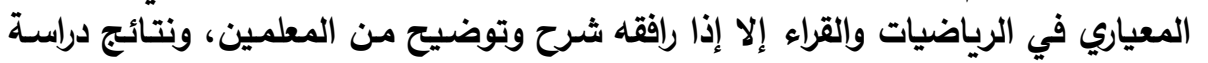

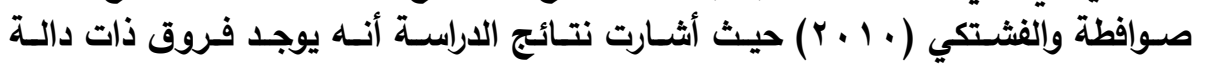
إحصائياً درجات الطلبة نحو استخدام الحاسوب يعزى للمجموعة التجريبية، ونتائيج دراسـة يوسف وأفولسبي(Yusuf \& Afolsbi, 2010) حيث توصلت نتائج الدراسـة إلى أن أن

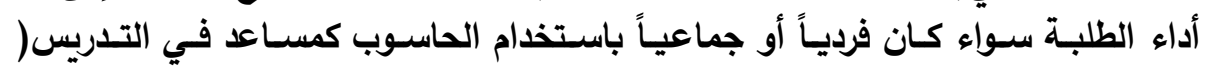

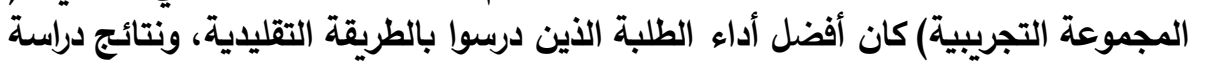

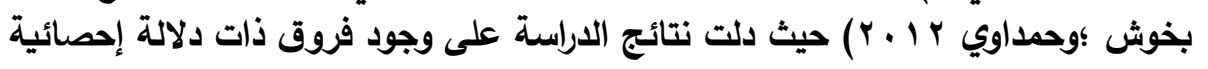

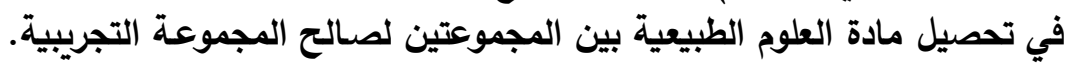

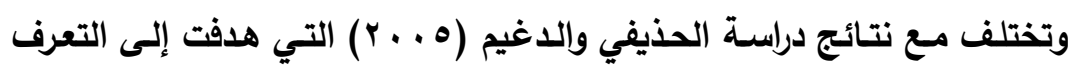

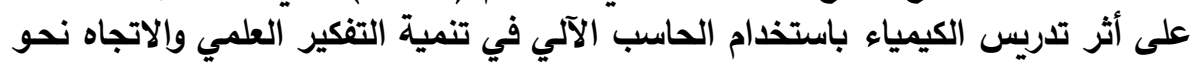

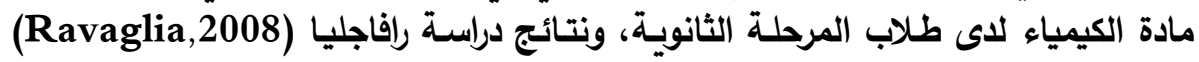

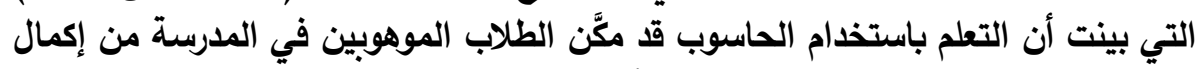

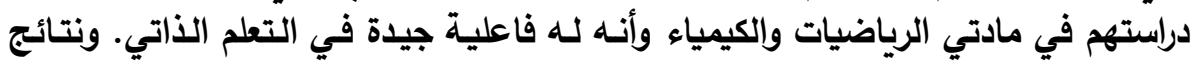

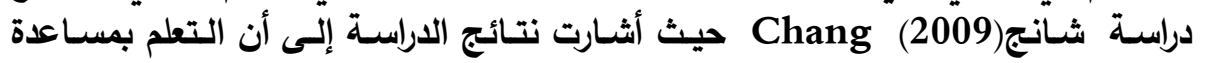

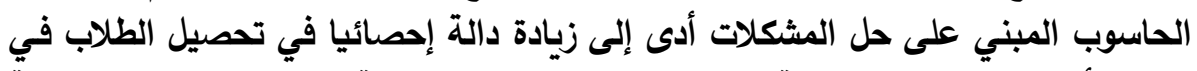

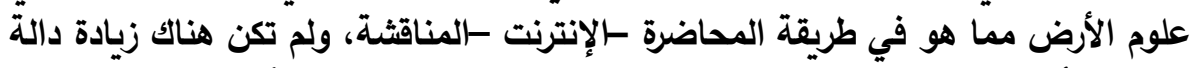

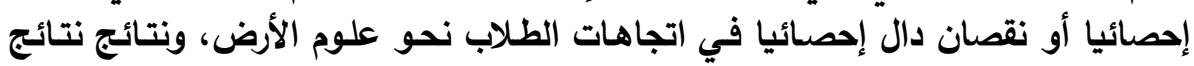

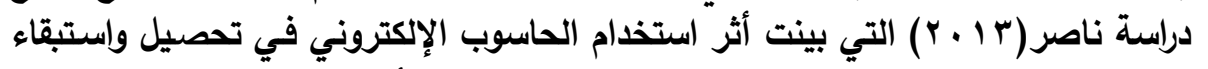

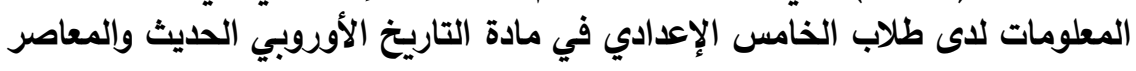
توصيات الاراسة: 
في ضوء نتائج الدراسة يمكن التوصية بما يلي:

1. توفير أجهزة الحاسب الآلي والمعامل المتكاملة في المدارس الحكومية المتوسطة للبنات، والاستعداد لأعمال الصيانة، وذلك لتمكين الطالبات من الاستئة الاستفادة واستخدام البرامج التعليمية المحوسبة، وخلق بيئة تعليمية حديثة.

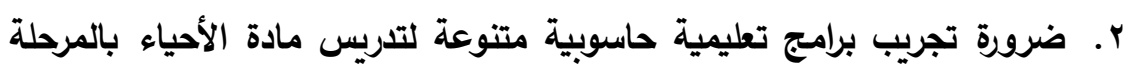

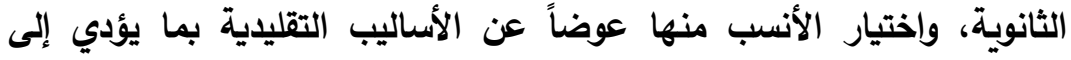
الرفع من مستوى التحصيل.

r. ينبغي إعادة تنظيم محتوى مادة الأحياء في المرحلة الثانوية بما يتناسب وأهمية البرامج التعليمية الحاسوبية، بما يؤدي إلى تنمية التحاء في التحصيل. ء. عقد ندوات وورش عمل مختلفة في مكاتب الإشراف من أجل إعداد وتدريب الإبه

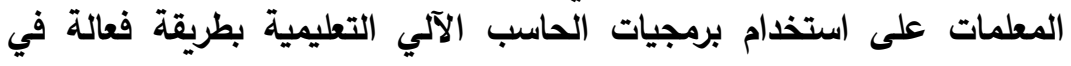

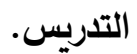

ه. إنتاج برامج تعليمية محوسبة ذات جودة في مقررات العلوم المختلفة، وتضافر

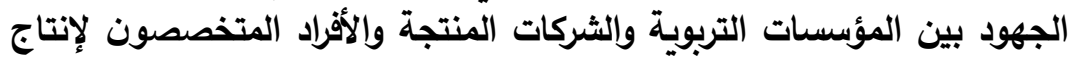

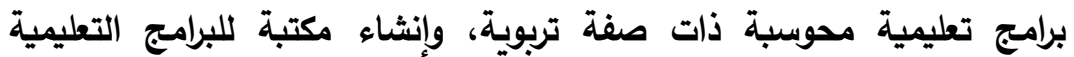

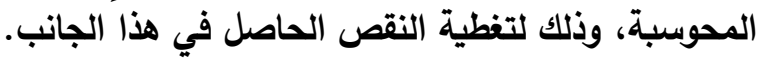

\section{مقترحات الدراسةة: - مقات}

ا. دراسة فاعلية استخدام البرامج التعليمية الحاسوبية في تدريس مقررات مختلفة

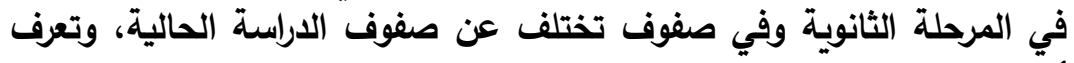
أثرها على التحصيل، والتفوق الدراسي والتهي والاحتفاظ بالتعلم.

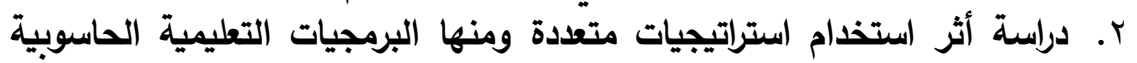
على التفوق الدراسي في مادة الأحياء والاتجاه نحوها.

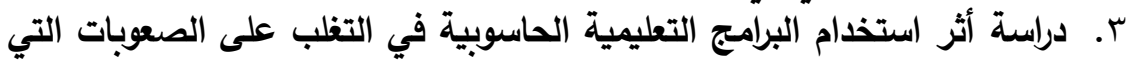

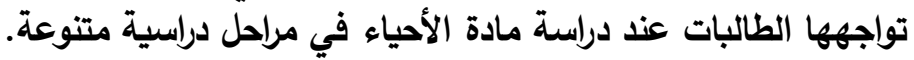
ع. إجراء دراسة لمعرفة اتجاهات الطالبات نحو استخدام الحاءلي مراحل دراسبة الآلي في تعلم 


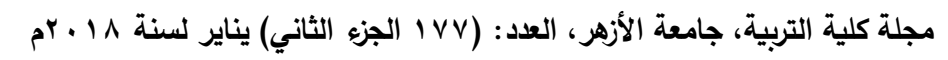

0. إجراء دراسة مقارنة بين استخدام البرمجيات الحاسوبية واستخدام معامل الأحياء

العادية للتعرف على أثرها في التعليم وأي الوسيلتين أفضيات الفيل وأسباب تميزها.

\section{المراجع}

$$
\text { أولا: المراجع العربية }
$$

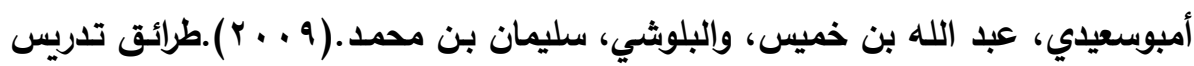

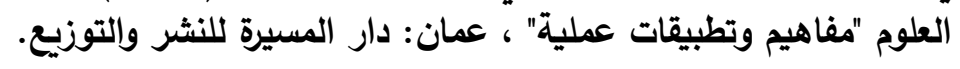

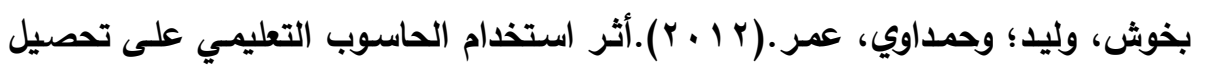

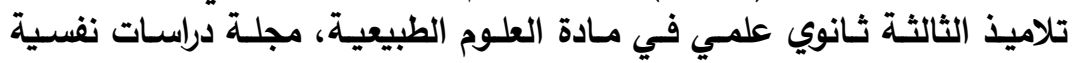

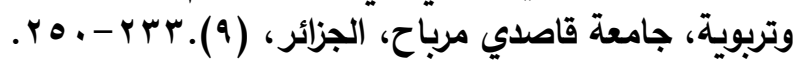

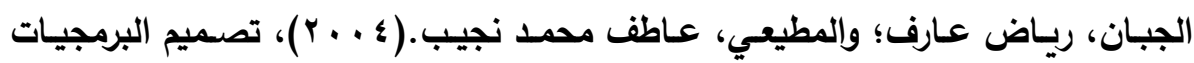
التعليمية وتقنيات إنتاجها، القاهرة: الدارئ عارف الذهبية. 


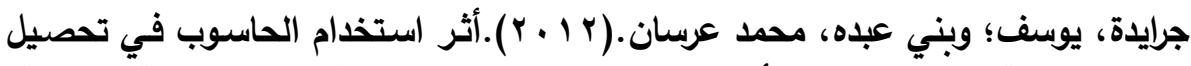

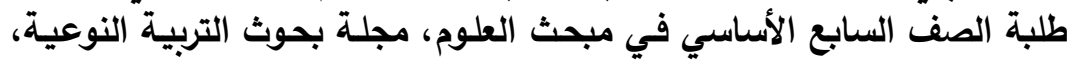

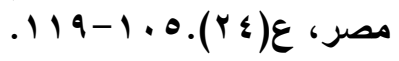

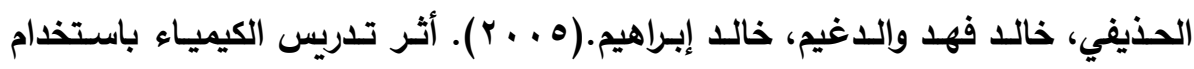

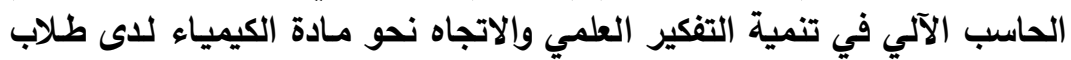

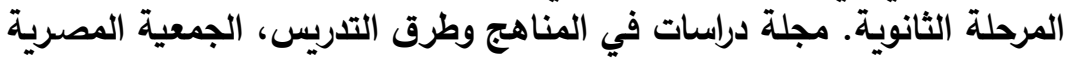

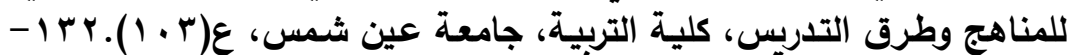

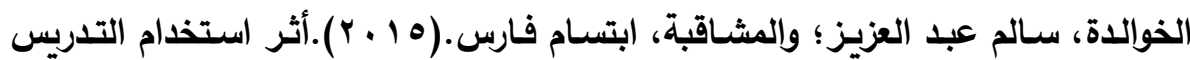

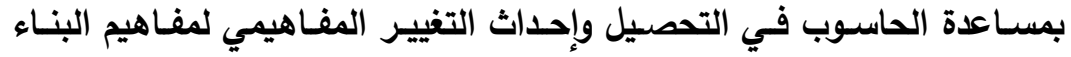

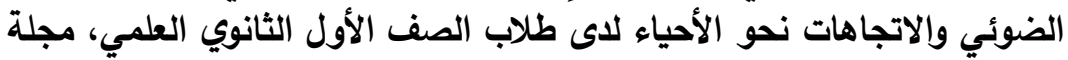

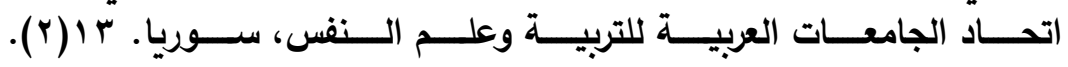
. rqq-rrq

الاسوقي، عيد أبو المعاطي، وتوفيق، رؤوف عزمي.( • ( ؟ ).تدريس العلوم بالكمبيوتر ، القاهرة: المكتب الجامعي الحديث.

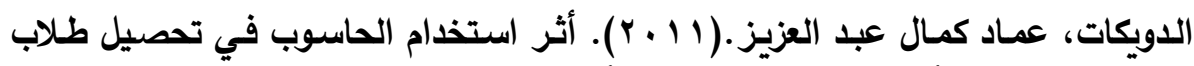

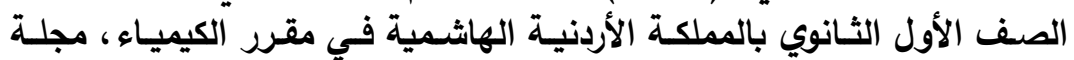

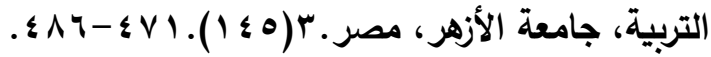

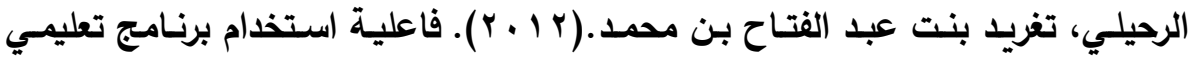

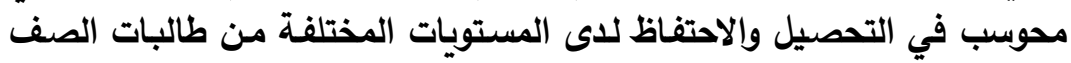

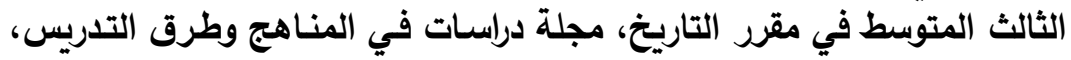

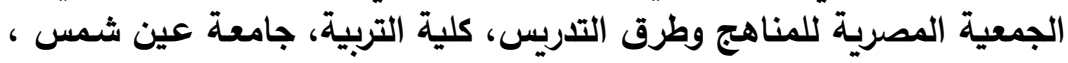
$.19 r-1 \leq 4.110 \varepsilon$

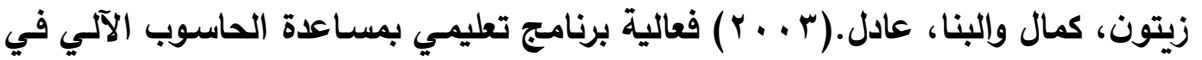

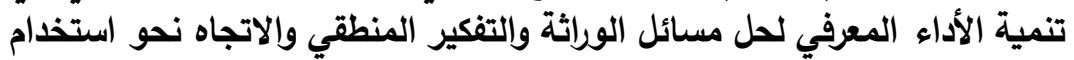

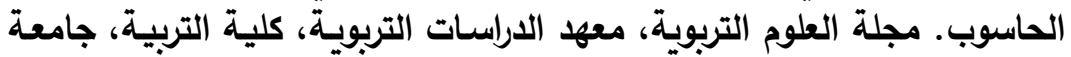

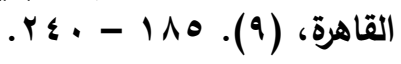

ساطور ، محمد مختار متولي، (1 . . Y)، فلسفة تصميم برامج تعليمية رقمية تفاعلية في

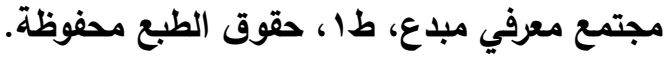

$$
-\wedge \varepsilon-
$$




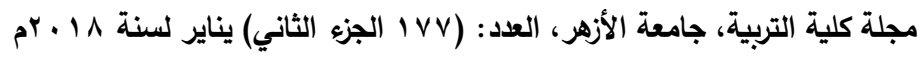

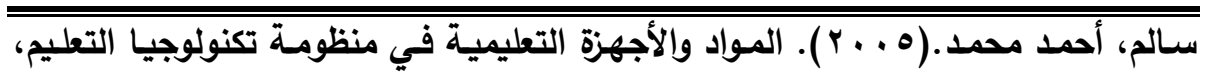

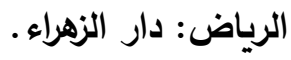

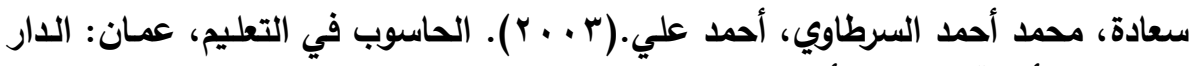
الأهلية للنشر، الأردن.

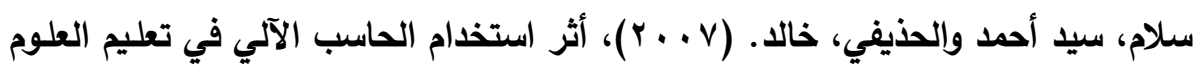

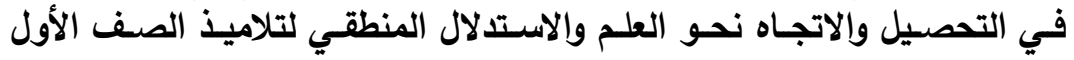

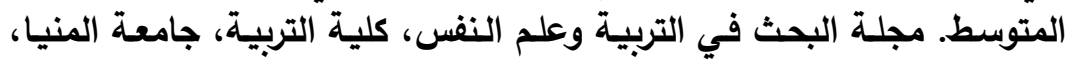

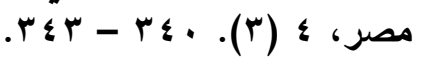

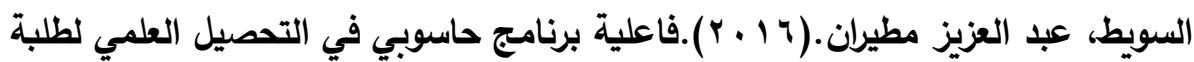

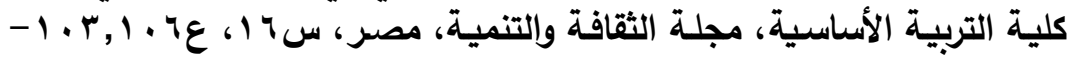

. Irr

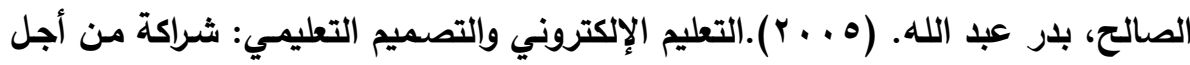

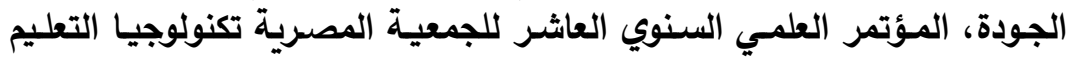

الإلكتروني ومتطلبات الجودة الثاملة، جامعة عين شمس، الجئ القاهرة.

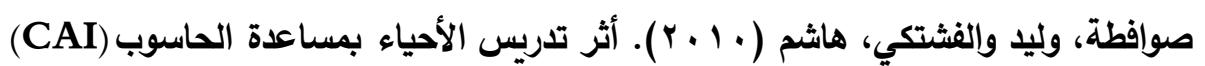

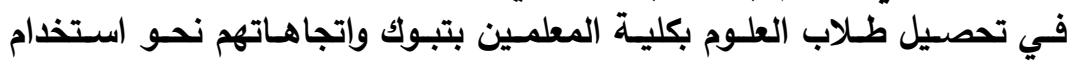

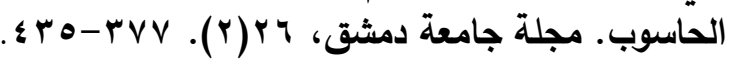

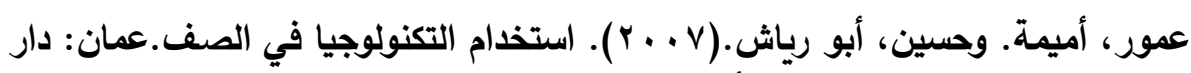

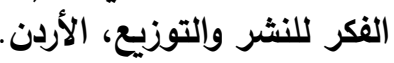

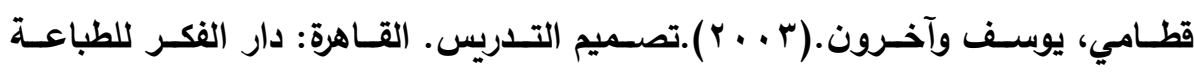
والنشر والتوزيع.

كاتوت، سحر أمين.(9 . . rم).طرق تدريس العلوم، ، عمان: دار دجلة.

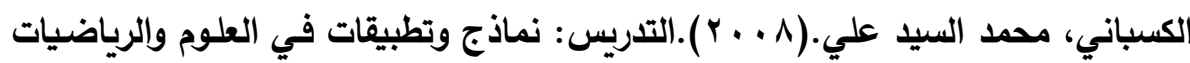
واللغة العربية والدراسات الاجتماعية، القاهرة: دار الفكر العربيد العربي.

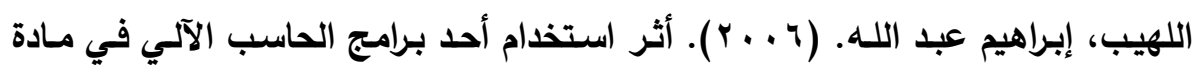

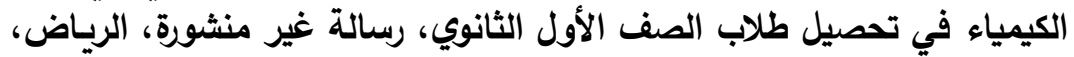
كلية التربية، جامعة الملك سعود.

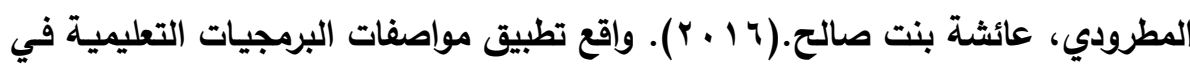

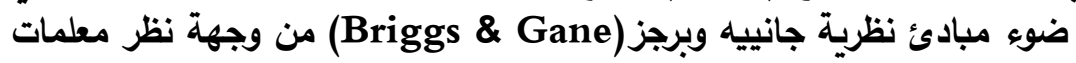




$$
\begin{aligned}
& \text { مادة الحاسب الآلي في مدينة الرياض، مجلة كلية التربية، جامعة بنها، مصر، }
\end{aligned}
$$

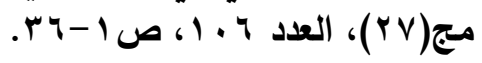

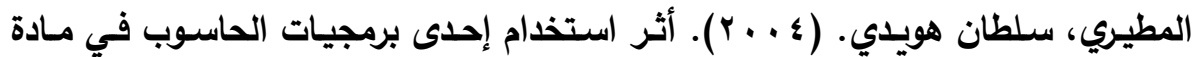

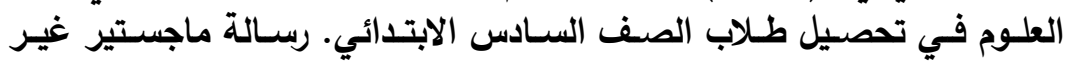

$$
\begin{aligned}
& \text { منشورة، الرياض، كلية التربية، جامعة الملك سعود. } \\
& \text { ناصر ، محمد طاهر .(r ( + r). أثر استخدام الحاسوب الإكترونسي في تحصيل واستبقاء }
\end{aligned}
$$

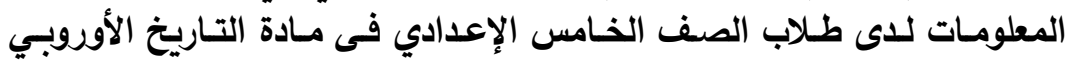

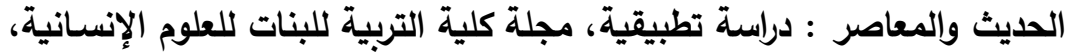

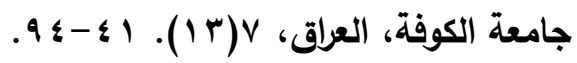

$$
\begin{aligned}
& \text { النعواشي، قاسم.( • ( • ؟). استخدام تكنولوجيا المعلومات والاتصالات في التعليم، عمان: }
\end{aligned}
$$

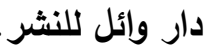

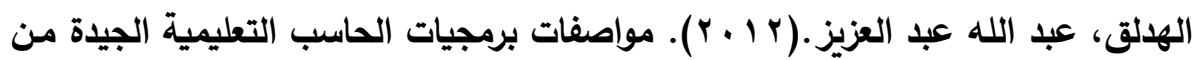

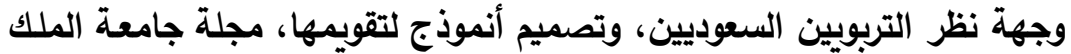

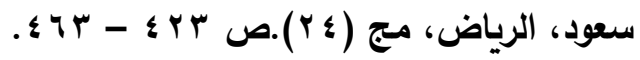

$$
\begin{aligned}
& \text { والنشر. } \\
& \text { ثانيا: المراجع الأجنبية }
\end{aligned}
$$

Chang. CY. (2009). Does Computer- Assisted Instruction \& Problem Solving Improved Science Outcomes? Apiower Study", the Journal of Educational Research. 95 (3). 150193.

Huang, S.(2008). The relationship between computer use and academic achievements. PhD thesis, University of North Texas. USA.

Oxford(1998). Dictionary of computing, England, Oxford science publication.

Ravaglia, A. (2008). computer based mathematics and Physics. Gifted Child Quarterly, 39 (1), 7-13. 


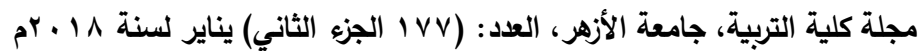

Seels, Barbara \& Glasgow, Rita .(1990). Exercises in instruct Design. Colam. Ohio, meraill publishing co.

Yusuf, M. \& Afolabi, A. (2010). Effects of computer assisted instruction (ACI) on secondary school students' performance in biology. Turkish Online Journal of Educational Technology, 9(1), 62-69. 